\title{
Reliability of reanalyses products in simulating precipitation and temperature characteristics over India
}

\author{
Nikhil Ghodichore ${ }^{1}, \mathrm{R}$ Vinnarasi $^{1}, \mathrm{C}$ T Dhanya ${ }^{1, *}{ }^{(}$and Somnath Baidya Roy ${ }^{2}$ \\ ${ }^{1}$ Department of Civil Engineering, Indian Institute of Technology Delhi, New Delhi 110 016, India. \\ ${ }^{2}$ Centre for Atmospheric Sciences, Indian Institute of Technology Delhi, New Delhi 110016, India. \\ *Corresponding author.e-mail: dhanya@civil.iitd.ac.in
}

MS received 27 January 2017; revised 11 February 2018; accepted 13 March 2018; published online 5 October 2018

Various reanalyses have been utilized in numerous climate related researches around the globe, however, there exists considerable biasedness in these products, especially in precipitation and temperature data. The ability of these reanalysis products to simulate the precipitation and temperature patterns is observed to be satisfactory at global scale, while it differs significantly at regional scale, especially over regions of high spatio-temporal heterogeneity such as India. Therefore, it is essential to evaluate the applicability and robustness of reanalyses in climate related research. The annual and seasonal variability in spatiotemporal patterns and trends of precipitation and temperature data, with respect to the IMD gridded data over 34 yrs, are evaluated for six global reanalyses namely, NCEP/NCAR Reanalysis (NCEP R1), NCEP-DOE AMIP-2 Reanalysis (NCEP R2), Climate Forecast System Reanalysis (CFSR), ECMWF Interim Reanalysis (ERA-Interim), Modern Era Retrospective Analysis for Research and Application Land only model (MERRA-Land) and JMA 55-year Reanalysis (JRA-55). The ability of the reanalyses was tested based on several factors such as statistical and categorical indices, spells and trends, for annual and seasonal daily values. Several regional and seasonal differences were observed, particularly over high rainfall regions such as Western Ghats and northeastern India. MERRA-Land is found to give the best results for precipitation over India, which is attributed to the updated forcing data using gauge-based precipitation observations. Similarly, ERA-Interim and JRA-55 exhibit better performance for temperature than other datasets. All reanalyses failed to correctly reproduce the trends in IMD data, for both precipitation and temperature. These observations will provide a better perception on the reliability and applicability of reanalyses for climate and hydrological studies over India.

Keywords. Reanalyses; IMD; precipitation; temperature; seasonal; spell; trend.

\section{Introduction}

Globally reanalysis datasets have been extensively used in research and other practical applications, primarily as a reliable substitute to the observed climatic datasets. Reanalysis products provide homogeneous, consistent and reliable long term data for various atmospheric variables. Some of the most frequently used global reanalyses are the datasets released by National Centers for

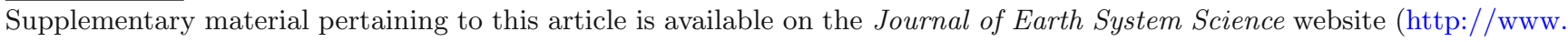
ias.ac.in/Journals/Journal_of_Earth_System_Science). 
Environmental Prediction (NCEP), European Centre for Medium Weather Forecasts (ECMWF), National Aeronautics and Space Administration (NASA) and Japan Meteorological Agency (JMA). Each dataset uses different observed data, data assimilation method, modelling techniques, and spatio-temporal resolution, which cause the performance of these products to be widely varying from region to region. Hence, the performance of different reanalyses in replicating the observed climate data at various regions is of utmost interest.

Several attempts have been made by researchers around the world to find out the most suitable reanalysis data product for a particular region or climate type by comparing it with the observed data. Inter-comparison of first generation reanalyses with the observed rain gauge and climate data as well as satellite derived datasets have been carried out by many researchers, at global and regional scales, in order to assess the reliability of two major hydrologic variables, i.e., precipitation and temperature datasets (Santer et al. 2004; Bosilovich et al. 2008; Lorenz and Kunstmann 2012; Vose et al. 2012; Manzanas et al. 2014; Blacutt et al. 2015), highlighting the differences in the performance of the reanalyses for different regions and climate zones. Later, second generation reanalysis models such as National Centre for Environmental Prediction Reanalysis-2 (NCEP R2), European Centre for Medium range Weather Forecast (ECMWF) 40-yr Reanalysis (ERA-40), Japan Meteorological Agency (JMA) 25-yr Reanalysis (JRA-25), ECMWF Interim Reanalysis (ERA-Interim) and Modern Era Retrospective Analysis for Research and Application (MERRA) were introduced and used in numerous studies (Hodges et al. 2011; Lin et al. 2014; Outten et al. 2013; Chen et al. 2014; Kang and Ahn 2015). ERA-Interim and MERRA were able to represent the inter-annual variability and climatology of global monsoon precipitation reasonably (Lin et al. 2014), which can be attributed to the higher resolution of these datasets as compared to the others. The reanalyses such as Climate Forecast System Reanalysis (CFSR), MERRA, ERA-Interim and JRA-25 datasets were able to perform better in the northern hemisphere, whereas in the southern hemisphere, only the performances of ERA-Interim and CFSR were comparable in analyzing the extratropical synoptic scale cyclones (Hodges et al. 2011). ERAInterim and NCEP reanalysis datasets were found to be in good agreement with the CMIP-5 model, results in terms of temperature trends and cooling pattern over the mid-latitude region (Outten et al. 2013). ERA-Interim and MERRA are reported to be closely replicating the precipitation and temperature dynamics over the Continental United States (Dhanya and Villarini 2017). The diurnal cycle over East Asia has been analyzed by Chen et al. (2014) using four reanalysis datasets, namely JRA-55, ERA-Interim, CFSR and MERRA and found that the interannual variation in the diurnal cycle was captured consistently by all reanalysis products over East Asia, of which JRA55 was able to provide good representation of the rainfall over Tibetan plateau and could capture the shift of the diurnal phase from the lowlands to the east. While analyzing the global energy and water balance using JRA-55, ERA-Interim, MERRA and CFSR, it was observed that all reanalyses exhibited energy imbalance at the surface and the top of atmosphere, which may be attributed to improper estimation of the incoming and outgoing heat fluxes (Kang and Ahn 2015). In addition to that, JRA-55 was found to be overestimating precipitation in the inter-tropical convergence zone and temperature in the south pacific convergence zone, compared to other datasets.

Reanalyses have been used by many studies to highlight specific climatological variations over Indian subcontinent (Misra et al. 2012; Kar and Rana 2014). The reanalysis datasets CFSR, ERAInterim and MERRA exhibited discrepancies in bias, trend and spatio-temporal variability in monsoon season and were not able to perform consistently for both monsoon season temperature as well as precipitation (Shah and Mishra 2014), while reproducing retrospective monsoon season droughts during the period 1980-2005. The seasonal variability in precipitation over Indian subcontinent was examined by Rana et al. (2015) using precipitation data from seven datasets including gridded observational data, satellite-derived data and reanalysis products, and noticed that CFSR and ERA-Interim overestimated the monsoon season precipitation variability over eastern India as compared to IMD data. While comparing the IMD gridded dataset with the various reanalysis products (CFSR, ERA-Interim, MERRA and JRA-25) and observational datasets (GPCP and APHRODITE), it was highlighted that among the reanalysis products, JRA-25 heavily underestimated rainfall during the pre-monsoon season, while ERA-Interim performed better than other reanalyses (Kishore et al. 2016). 
The literature review clearly shows that existing studies have evaluated the performance of reanalyses products mostly in the context of monsoon precipitation, but not with regards to temperature. Moreover, the performance of some of the new reanalysis products such as 'JRA-55' (Ebita et al. 2011), a 55-yr reanalysis by JMA, and MERRALand (Reichle et al. 2011), a revised version of the MERRA system's land component, have never been evaluated over the Indian subcontinent. This study attempts to fill these gaps by conducting a comprehensive evaluation of the capability of the latest reanalysis products to capture the mean and spatio-temporal variability of precipitation and temperature observations from India Meteorological Department (IMD). Apart from assessing reliability of reanalyses products, this study may also help in enhancing our understanding of climate and its variability over India.

\section{Data and methods}

\subsection{Data}

\subsubsection{IMD}

The gridded precipitation and temperature datasets from IMD are used as the reference datasets. These gridded datasets are prepared from station data using a modified version of the angular distance weighing algorithm (Shepard 1968). The gridded daily precipitation data is available at a resolution of $0.25^{\circ} \times 0.25^{\circ}$ covering India from $66^{\circ}$ to $100^{\circ} \mathrm{E}$ and $6^{\circ}$ to $39^{\circ} \mathrm{N}$, for a period of $113 \mathrm{yr}$ from 1901 to 2013 (Pai et al. 2014). This dataset accurately captures the orographic influence of precipitation and demarcate the heavy and low rainfall regions. The IMD gridded daily mean temperature data is available at $1^{\circ} \times 1^{\circ}$ resolution for a period of $63 \mathrm{yr}$ from 1951 to 2013 (Srivastava et al. 2009). This dataset is extensively used for analysis of extremes (e.g., Dash and Kjellstrom 2011; Deshpande et al. 2016; Vinnarasi and Dhanya 2016).

\subsubsection{NCEP R1 and R2}

NCEP, in collaboration with National Centre for Atmospheric Research (NCAR) released the first reanalysis product NCEP-NCAR reanalysis 1 (R1) (Kalnay et al. 1996), using Climate Data Assimilation System (CDAS) with a frozen forecast/ analysis model. The data is available from 1948 onwards at a spatial resolution of $2.5^{\circ}$ with 28 vertical levels at 6 -hourly time step. Later, NCEP developed the NCEP reanalysis 2 (R2) (Kanamitsu et al. 2002), in collaboration with the United States Department of Energy (US-DOE), which rectified the known errors in the earlier reanalysis by incorporating updated forecast model and data assimilation model. NCEP R2 provides global data at similar spatial resolution and time period as the earlier NCEP R1 dataset. The NCEP reanalysis datasets can be downloaded from Earth System Research Laboratory (ESRL) of National Oceanic and Atmospheric Administration (NOAA) (https://www.esrl.noaa.gov/psd/ data/gridded/data.ncep.reanalysis.html).

\subsubsection{CFSR}

The third generation product called Climate Forecast System Reanalysis (CFSR) was released by NCEP, which incorporated major advances such as higher resolution of T382 $(\sim 38 \mathrm{~km})$ with 64 vertical levels reaching up to $0.26 \mathrm{hPa}$ from surface. CFSR utilizes NCEP coupled forecast system model, consisting of a spectral atmospheric model and a modular ocean model and uses three dimensional variational (3D-VAR) data assimilation, based on the grid-point statistical interpolation (GSI) scheme (Saha et al. 2010). CFSR data is available at 6-hourly time step from 1979 to 2010 and CFSv2, an extension of CFSR data is available from 2011 onwards from NCAR's Research Data Archive (https://rda.ucar.edu).

\subsubsection{ERA-Interim}

ERA-Interim is the latest reanalysis from ECMWF, which replaced its older version, ERA-40 (Uppala et al. 2005) and incorporates four dimensional variational (4-D VAR) data assimilation, variational bias correction for satellite radiances and other enhancements in data handling. The horizontal resolution of ERA-Interim is T255 $(\sim 80 \mathrm{~km})$ with 60 vertical hybrid levels reaching to $0.1 \mathrm{hPa}$ from surface. ERA-Interim data is available at 6hourly time step from 1979 to present (Dee et al. 2011) at the ECMWF portal (http://apps.ecmwf. int/datasets/data/interim-full-daily).

\subsubsection{MERRA-Land}

The MERRA reanalysis data (Rienecker et al. 2011) from NASA uses 3D-VAR data assimilation system. MERRA-Land, however, is a land-surface only dataset, which is produced by improving 
the land component of the MERRA system. Further details regarding the improvements made in MERRA-Land can be found in Reichle et al. (2011). MERRA-Land, having a resolution of $0.5^{\circ}$ latitude by $0.67^{\circ}$ longitude with 72 vertical levels reaching $0.01 \mathrm{hPa}$ from surface, is available at hourly time step since 1980 from NASA's Goddard Earth Sciences Data and Information Services Center (GES DISC) (https://disc.sci.gsfc.nasa.gov/ mdisc).

\subsubsection{JRA-55}

JRA-55 is the second reanalysis product from JMA employing 4D-VAR data assimilation method and variation bias correction for satellite data, and is an improved version of Japanese $25 \mathrm{yr}$ reanalysis (JRA-25) (Onogi 2007). The global horizontal resolution of JRA-55 is reduced Gaussian TL319 $(\sim 55 \mathrm{~km})$ with 60 horizontal levels up to $0.1 \mathrm{hPa}$, and is available at 6-hourly timestep for a period of 55 yr starting from 1958 (Ebita et al. 2011) from NCAR's Research Data Archive (https://rda.ucar. edu/datasets/ds628.0).

Considering the period of availability of all datasets, the analysis period is selected as 1980 2013 , and the extent is from $5^{\circ}$ to $38^{\circ} \mathrm{N}$ latitudes and $60^{\circ}$ to $100^{\circ} \mathrm{E}$ longitudes. The variables chosen for comparison are daily precipitation and temperature at $2 \mathrm{~m}$ height above ground surface. All the precipitation and temperature datasets are converted from sub-daily to daily time scales ( $\mathrm{mm} /$ day and ${ }^{\circ} \mathrm{C}$ units respectively for daily precipitation and temperature). Reanalyses provide temperature data at four times a day, corresponding to 0000 , 0600, 1200 and 1800 UTC. The daily mean temperature was calculated by averaging the values of temperature at these four times for each day. The salient features of the reanalyses used in this study are shown in table 1.

\subsection{Processing of the datasets}

Since the datasets have different spatial resolutions, a common grid of $0.5^{\circ} \times 0.5^{\circ}$ is chosen in order to facilitate the comparison of precipitation, and the reanalyses are re-gridded to $0.5^{\circ} \times 0.5^{\circ}$ resolution. Likewise, for comparison of temperature data, the reanalyses are re-gridded to $1^{\circ} \times 1^{\circ}$. The data is further divided into three seasons, i.e., pre-monsoon [February-May (FMAM)], monsoon [June-September (JJAS)] and post-monsoon

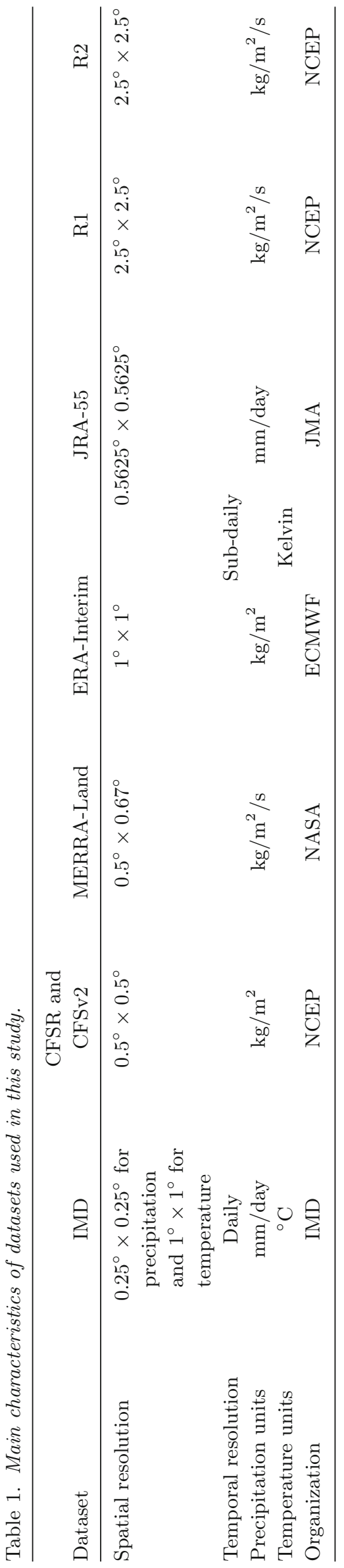


Table 2. A $2 \times 2$ contingency table for precipitation threshold of $P \mathrm{~mm}$.

\begin{tabular}{|c|c|c|c|}
\hline & & \multicolumn{2}{|c|}{ Reference dataset (IMD) } \\
\hline & & $\begin{array}{c}\text { Event detected (yes) } \\
\text { IMD }>P\end{array}$ & $\begin{array}{c}\text { Event not detected (no) } \\
\mathrm{IMD} \leq P\end{array}$ \\
\hline \multirow[t]{2}{*}{ Reanalysis dataset $\left(R_{\text {ana }}\right)$} & $\begin{array}{l}\text { Event detected (yes) } \\
R_{\text {ana }}>P\end{array}$ & Hits $(H)$ & False alarms $(F)$ \\
\hline & $\begin{array}{l}\text { Event not detected (no) } \\
R_{\text {ana }} \leq P\end{array}$ & $\operatorname{Miss}(M)$ & Correct rejections $(T)$ \\
\hline
\end{tabular}

[October-January (ONDJ)], considering the fact that most of the large scale annual variations of precipitation and temperature can be covered under these seasonal designations. Only land points are considered for all the datasets.

\subsection{Evaluation techniques and indices}

Several statistical indices are used to analyze the reanalysis products with respect to the reference of the IMD data. The bias (reanalysis data-IMD data) and inter-annual variability in precipitation and temperature are estimated for all products for all seasons. The seasonal analysis for precipitation (temperature) is carried out by calculating the frequency of wet (warm) and dry (cool) days and spells for all three seasons. In this study, the days receiving rainfall greater than $2.5 \mathrm{~mm} /$ day are considered as wet days, whereas those receiving lower than $2.5 \mathrm{~mm} /$ day are considered as dry days. Wet spells are defined as the continuous period of wet days immediately followed by a dry day. Similarly, dry spells are defined as the continuous period of dry days immediately followed by a wet day. In this study, we have used a threshold of $2.5 \mathrm{~mm} /$ day (Pai and Rajeevan 2007; Dash et al. 2009) for defining wet day, i.e., day receiving more than $2.5 \mathrm{~mm} /$ day are considered a wet day and a spell length of minimum 3 days (maximum spell length may vary for grids) is considered (Rajeevan et al. 2010; Sushama et al. 2014; Vinnarasi and Dhanya 2016; Chaudhary et al. 2017). A threshold of $2.5 \mathrm{~mm} /$ day is used by most studies considering that rainfall less than $1 \mathrm{~mm} /$ day only contributes to evaporation (Epifani et al. 2004; Tilya and Mhita 2007). Additionally, IMD defined rainfall less than $2.5 \mathrm{~mm} /$ day as very little rainfall (Vinnarasi and Dhanya 2016). Similar approach is followed for temperature analysis, where reanalyses are assessed on the basis of an index termed 'warm days'. In this study, warm days are defined as the days having mean temperature above the climatological mean temperature for the corresponding grid. It is to be noted that the threshold of warm day will vary spatio-temporally over India. Different regions will have different thresholds, which will moreover vary in seasons as well. Warm spells are continuous period of warm days, followed by a cool day. The minimum length of warm spell is considered as 1 day.

The existence of any monotonic increasing or decreasing trend is checked, using non-parametric Mann-Kendall test at 10, 5 and 1\% significance levels. Moreover, a non-parametric moving block bootstrap resampling technique is used in this study. Along with these indices, a $2 \times 2$ contingency table (shown in table 2 ) is prepared for all reanalyses, with IMD as the observation data. Three categorical indices, viz., False Alarm Ratio (FAR), Probability of Detection (POD) and Critical Success Index (CSI) based on the contingency table are calculated for the frequency of wet and dry days for precipitation datasets and for warm and cold days for the temperature datasets. Table 3 shows the formulae, range and significance of these categorical indices. POD signifies the fraction of observations correctly detected by the model. POD value of $1(0)$ represents that all (none) observed events were correctly simulated by the model. On the other hand, FAR represents the fraction of events simulated by the models, but did not occur in the field. The ideal value for FAR is 0 , which signifies that none of the observed events were incorrectly simulated by the reanalyses. CSI combines the features of both FAR and POD and corresponds to the overall skill of simulation with respect to the observations. CSI ranges from 0 to 1 , where 0 signifies no skill and 1 represents perfect skill. Further details about the contingency table and various categorical indices can be found in Wilks (2011). The ability of various reanalyses in reproducing the magnitude of rainfall and temperature and their pattern over India is hence evaluated. 
Table 3. Definition of various categorical skill indices.

\begin{tabular}{lcccc}
\hline Score & Formula & Range & Ideal value & Significance \\
\hline Probability of detection (POD) & $\frac{H}{H+M}$ & 01 & 1 & $\begin{array}{l}\text { Fractions of observed events in IMD that } \\
\text { were accurately detected by } R_{\text {ana }}\end{array}$ \\
False alarm ratio (FAR) & $\frac{F}{H+F}$ & 01 & 0 & $\begin{array}{r}\text { Fractions of detected events in } R_{\text {ana }} \text { for } \\
\text { which observed event did not occur in IMD }\end{array}$ \\
Critical success ratio (CSI) & $\frac{H}{H+M+F}$ & 01 & 1 & $\begin{array}{l}\text { Fractions of observed and/or detected } \\
\text { events that were correctly predicted, when } \\
\text { correct rejections have not been considered }\end{array}$ \\
\hline
\end{tabular}
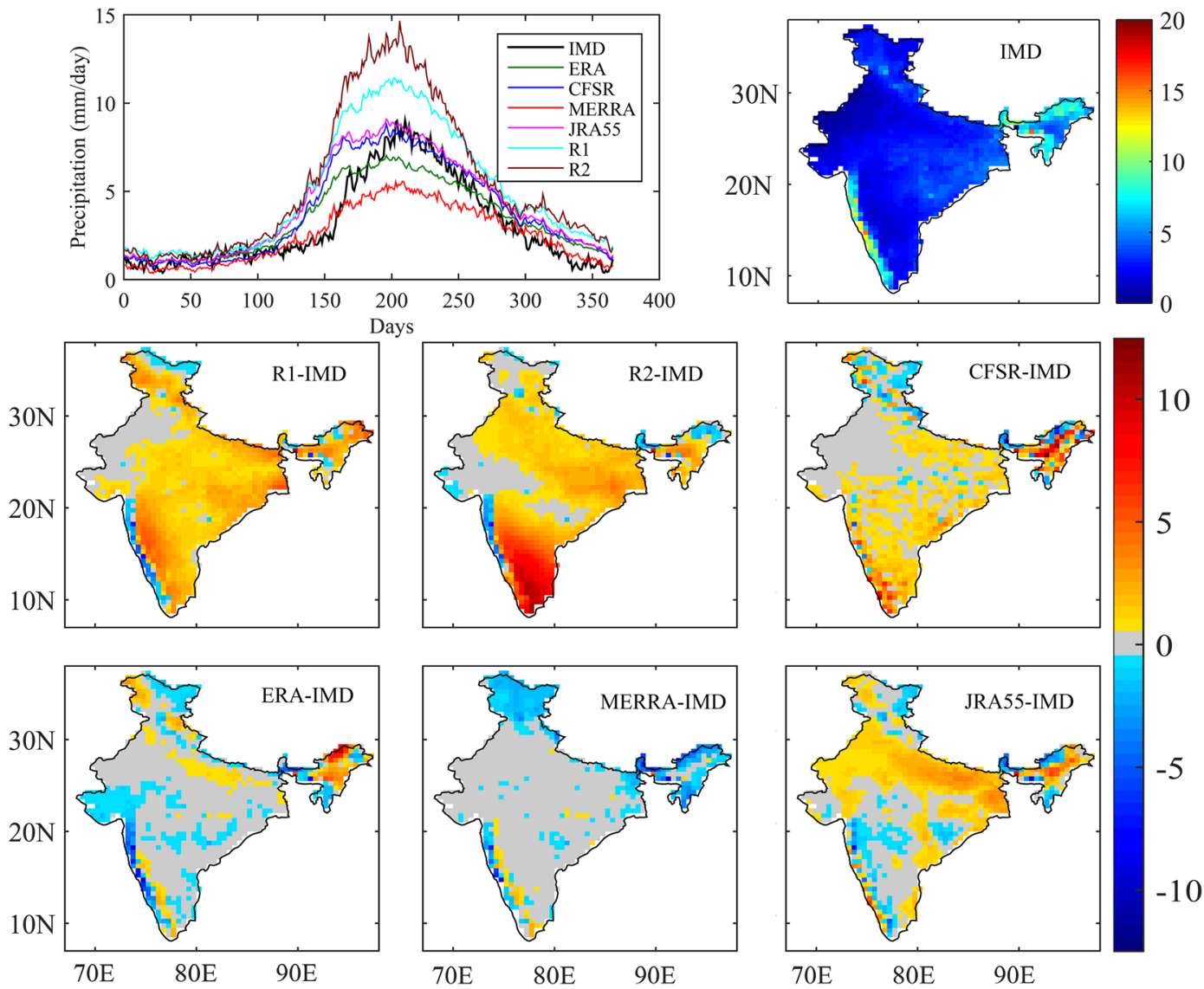

Figure 1. Climatological annual cycle and spatial distribution of mean annual precipitation (mm/day) of IMD gridded data from 1980 to 2013; mean precipitation difference of various datasets with respect to IMD gridded dataset are also shown. It is observed that MERRA-Land is able to match the mean annual precipitation over most of India.

\section{Results and discussion}

\subsection{Analysis of precipitation characteristics}

\subsubsection{Characteristics of annual precipitation}

The spatial distribution of the mean annual precipitation in IMD dataset and the precipitation bias in the reanalyses are shown in figure 1. The highest mean precipitation is observed over the Western Ghats and the northeastern regions (8-15 $\mathrm{mm} /$ day), whereas the average precipitation over rest of India is less than $6 \mathrm{~mm} /$ day. Significant regional discrepancies can be observed in the reanalyses, especially over regions receiving high rainfall such as the Western Ghats and northeast, which are known to experience intense convection as well as orographic lifting (Pattanaik and Rajeevan 2010). NCEP R1, R2 and CFSR overestimate the precipitation over the southern parts of India, whereas ERA-Interim overestimates the precipitation over the foothills of Himalayas and northeast, while it underestimates over western 
India. JRA-55 tends to overestimate precipitation over the northern India, which may be due to spin-down problem in the JRA-55 reanalysis system, leading to excessive rainfall after the start of forecasts (Kobayashi et al. 2015). However, MERRA-Land exhibits similar rainfall distribution in comparison with IMD throughout India, with the exception of Western Ghats, northernmost and northeastern India, where it tends to underestimate, which can be attributed to the correction of data using coarse resolution GPCP precipitation (Reichle et al. 2011). Underestimation of precipitation in regions receiving high rainfall may be observed in MERRA-Land, which may be due to the difference between the GPCP and IMD precipitation values (Shah and Mishra 2014). The climatological annual cycle for IMD data and other reanalyses are also shown in figure 1. NCEP R1 and R2 overestimate precipitation substantially throughout the year, especially during monsoon. CFSR and JRA-55 also seems to overestimate precipitation; however, their peaks lie in range with that of IMD. ERA-Interim, on the other hand, underestimates precipitation during monsoon and overestimates it during the other seasons. It is noted that the onset of monsoon in IMD dataset matches only with MERRALand, with close match at other periods. However, the peak monsoon rainfall is underestimated by
MERRA-Land. The climatological annual cycle reveals the disparity between the observed IMD data and reanalyses at distinct seasons. Hence, for further analyses, the dataset is further subdivided into pre-monsoon, monsoon and postmonsoon, as mentioned in section 2.3 , to get a clear picture of the distribution of precipitation in different seasons.

\subsubsection{Daily precipitation analysis: Statistical indices}

The statistical relation between IMD dataset and other reanalyses has been analyzed using density scatter plots as shown in figure 2. The corresponding linear equation, correlation coefficient and root mean square error is also shown along with the scatter plot. All reanalyses show high spread and RMSE values, with the highest value observed in NCEP R2 dataset, while the lowest in ERAInterim.

\subsubsection{Daily precipitation analysis: Categorical indices}

The precipitation characteristics of the IMD dataset and the reanalyses are further assessed using categorical indices, namely FAR, POD and CSI. These indices are computed for the occurrence
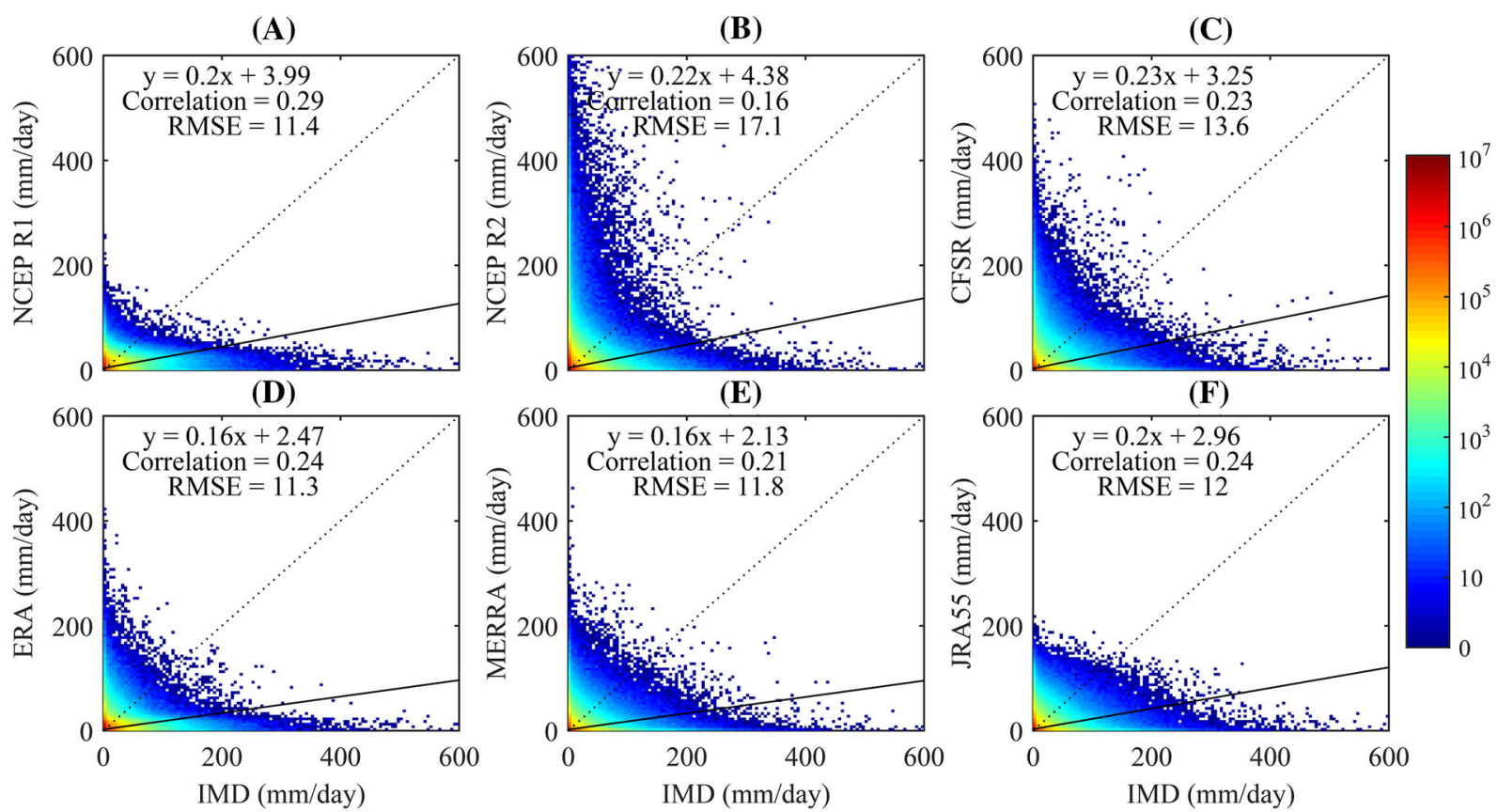

Figure 2. Density scatter plots of daily precipitation values between IMD and other reanalysis products for the period 1980-2013. The black dashed line is the 1:1 reference line and solid line is the best fit line between IMD and reanalysis data. The number of counts in the colour bar is denoted per $5 \mathrm{~mm}$ bin. 

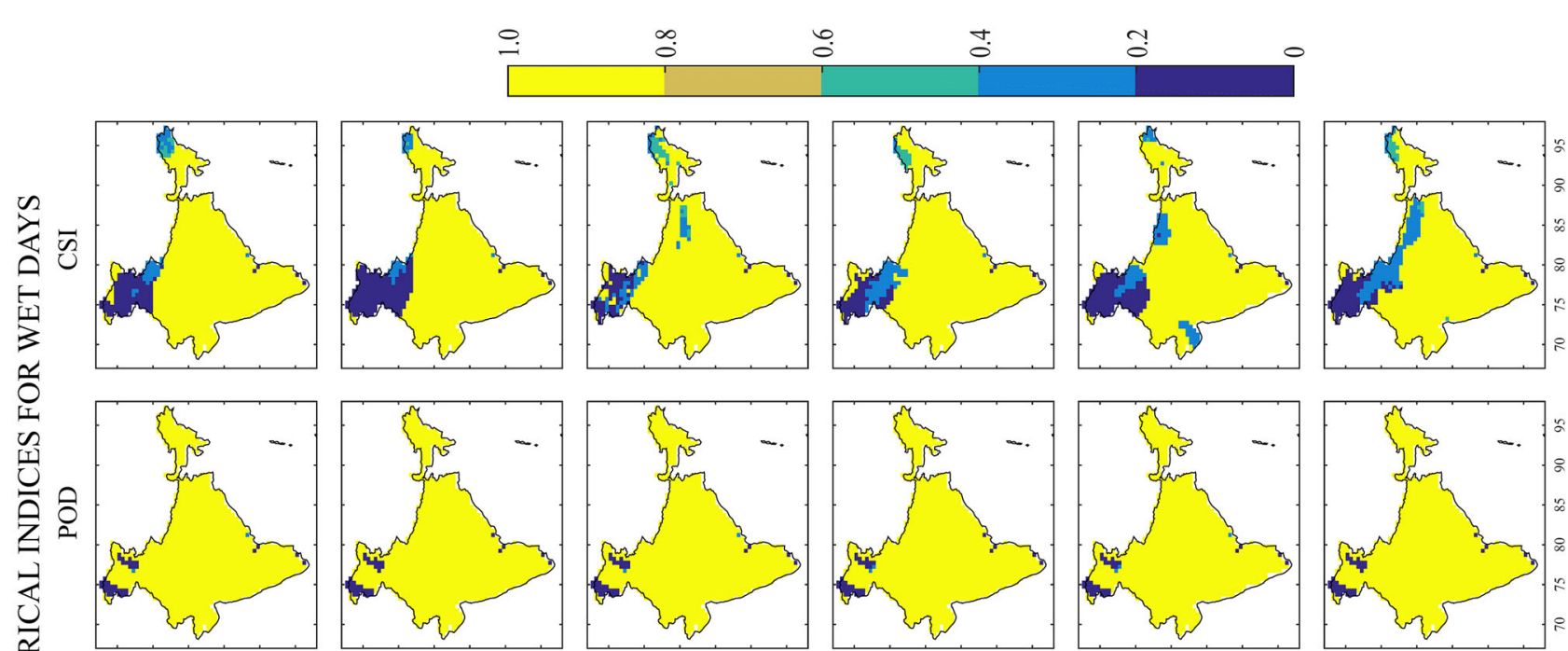

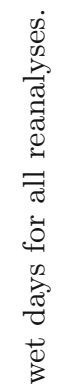
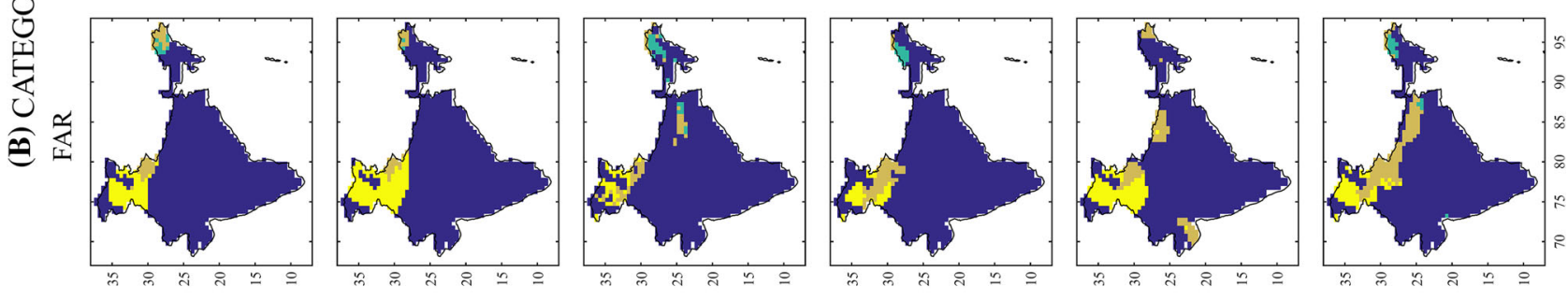

I너 dᄏON

2ช d

บSAว

vy

vуㅕㄴ

sSVYI

우

$\stackrel{\infty}{0} \quad \stackrel{0}{0}$

$\stackrel{0}{0}$

ֻุด
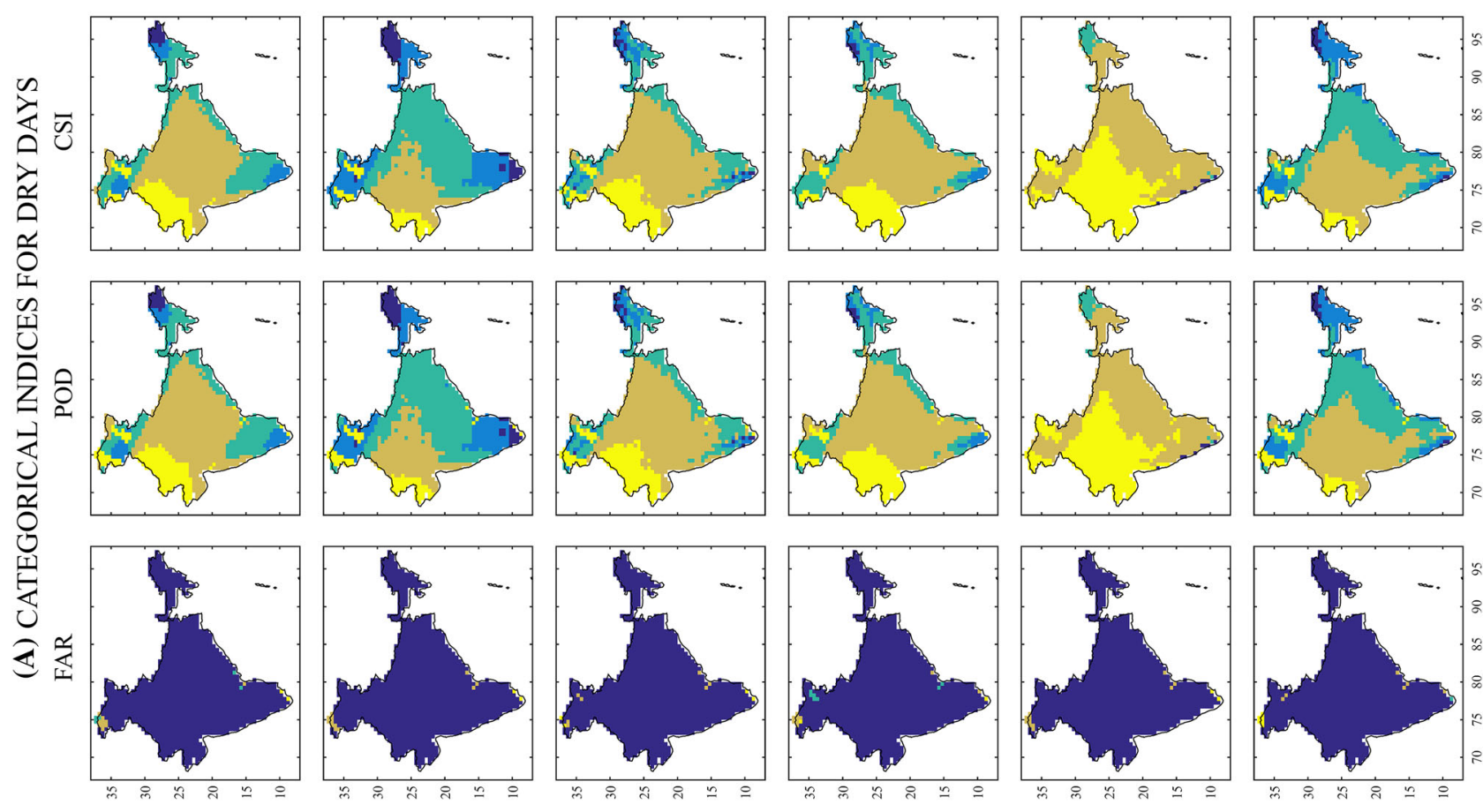

YSAD

고
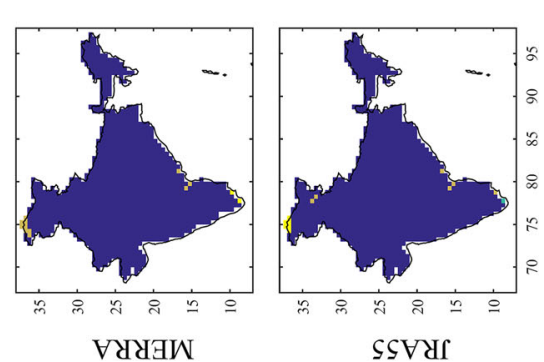

ऽऽVUI 
of dry and wet days, and spatial plots for the same are shown in figure 3 . In case of dry days, almost all grids show low FAR, while POD and CSI decreases from west to east. All reanalyses show low performance over the northeastern regions. JRA-55 and NCEP datasets exhibit lower POD and CSI over most of India, while MERRA-Land shows better values than all other reanalyses. In case of wet days, most of the grids show low FAR and high POD and CSI, except for northernmost regions. The categorical indices are computed for all the datasets with varying threshold values $(0.1-100 \mathrm{~mm} /$ day) for wet days (not shown here). The value of FAR increases, while POD decreases consistently with increasing threshold values, suggesting that the ability of the reanalyses in detecting wet days decreases as threshold increases. CFSR shows highest POD, while NCEP R1 shows the highest FAR for wet days among the reanalyses. (Refer supplementary figure S17 for variation of FAR and POD in wet days with increasing thresholds for all reanalyses.)

\subsubsection{Seasonal characteristics}

The statistical relation between the reanalyses and observed daily precipitation for various seasons in terms of root mean square error, correlation coefficient and standard deviation is summarized using Taylor diagram (Taylor 2001), as shown in figure 4 . The diagram indicates that the reanalyses reproduce the spatial rainfall patterns in reference dataset with a correlation of greater than $0.8,0.6$ and 0.8 in case of FMAM, JJAS and ONDJ seasons, respectively. For all seasons, MERRA-Land correlates well with IMD precipitation data as compared to other reanalyses. First generation datasets like NCEP R1 and R2 exhibit least correlation with the reference data, which may be due to the data assimilation system used in $\mathrm{R} 1$ and $\mathrm{R} 2$ (Saha et al. 2010).

Spell analysis. The central Indian regions remain comparatively dry during FMAM and ONDJ, with mild rainfall received by the north and northeast regions. During JJAS, India receives majority of its rainfall as a result of the incoming southwest monsoon winds. Heavy rainfall is experienced in the Western Ghats and northeast India, which can be attributed to the location and topography. The seasonal variation in the frequency of wet and dry days and spell are shown in figure 5, in the form of boxplots. The IMD data shows that the frequency of wet days is highest in the northeast during FMAM and JJAS. However, during ONDJ, south India experiences highest number of wet days. All reanalyses mostly overestimate the frequency of wet days, especially during monsoon. NCEP R1 and R2 heavily overestimate the number of wet days, while CFSR, ERA-Interim and JRA-55 overestimate over entire eastern half of India. MERRA-Land shows better results than other reanalyses, but still overestimates wet days over large patches. (See supplementary figures S1, S3, S5 and S7 for spatial plots of frequency of wet/dry days and spells for all reanalyses).

All reanalysis data products satisfactorily reproduce the major features of precipitation distribution for the pre-monsoon (FMAM) and

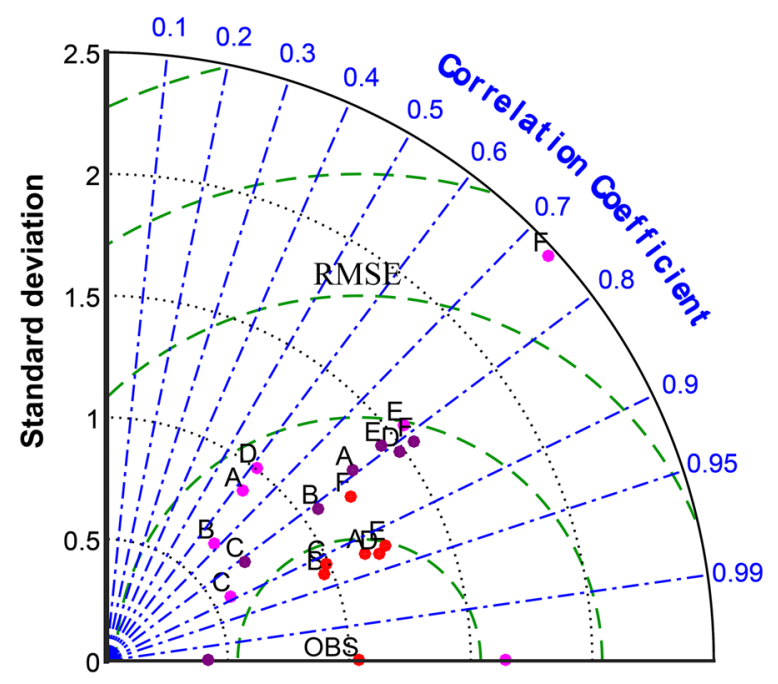

\section{$\mathrm{A}=\mathrm{CFSR}$ \\ $\mathrm{B}=\mathrm{ERA}$-Interim \\ $\mathrm{C}=$ MERRA-Land \\ $\mathrm{D}=\mathrm{JRA}-55$ \\ $\mathrm{E}=\mathrm{NCEP}-\mathrm{R} 1$ \\ $\mathrm{F}=\mathrm{NCEP}-\mathrm{R} 2$}

Premonsoon

Monsoon

Postmonsoon

Figure 4. Taylor plot of the seasonal precipitation. 

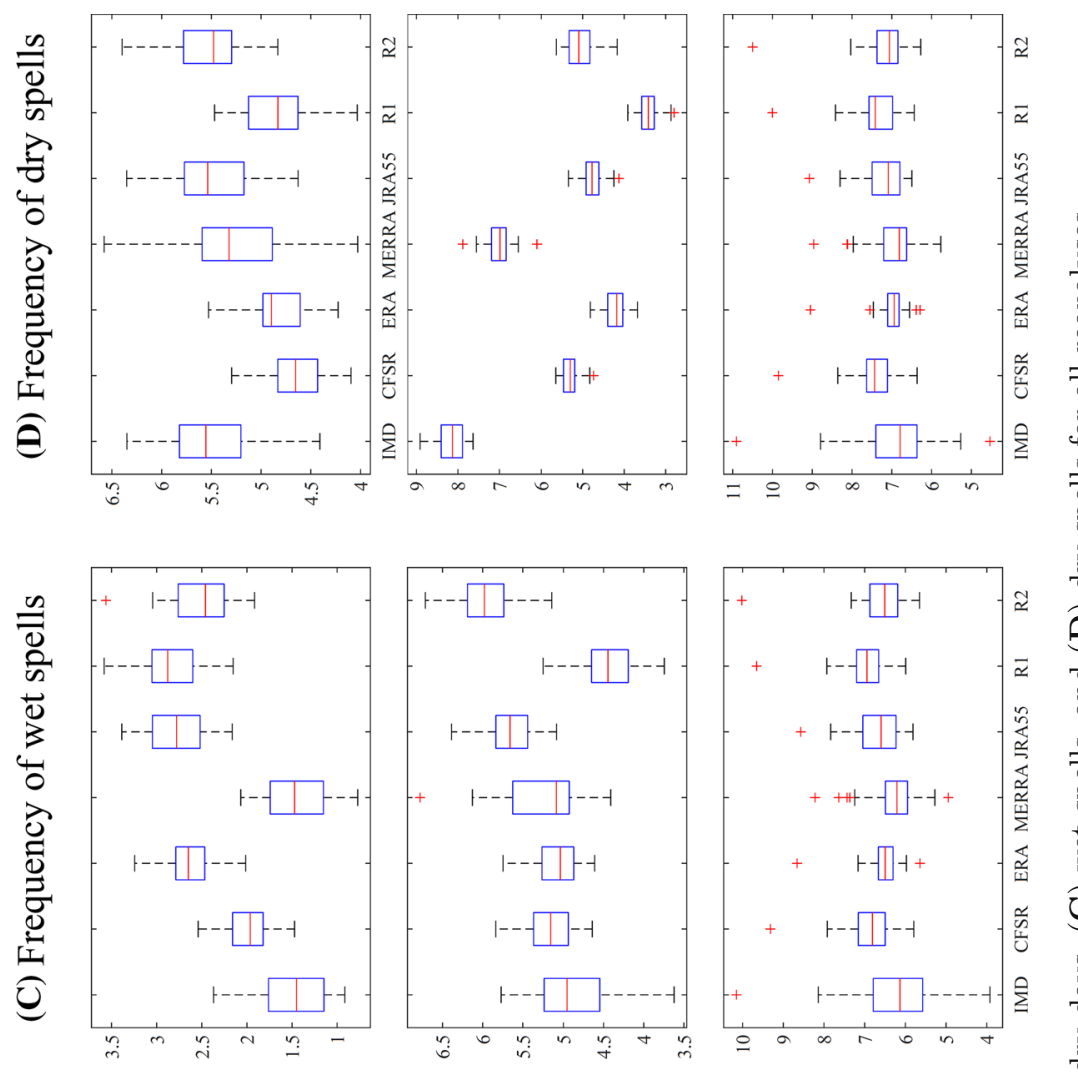

i
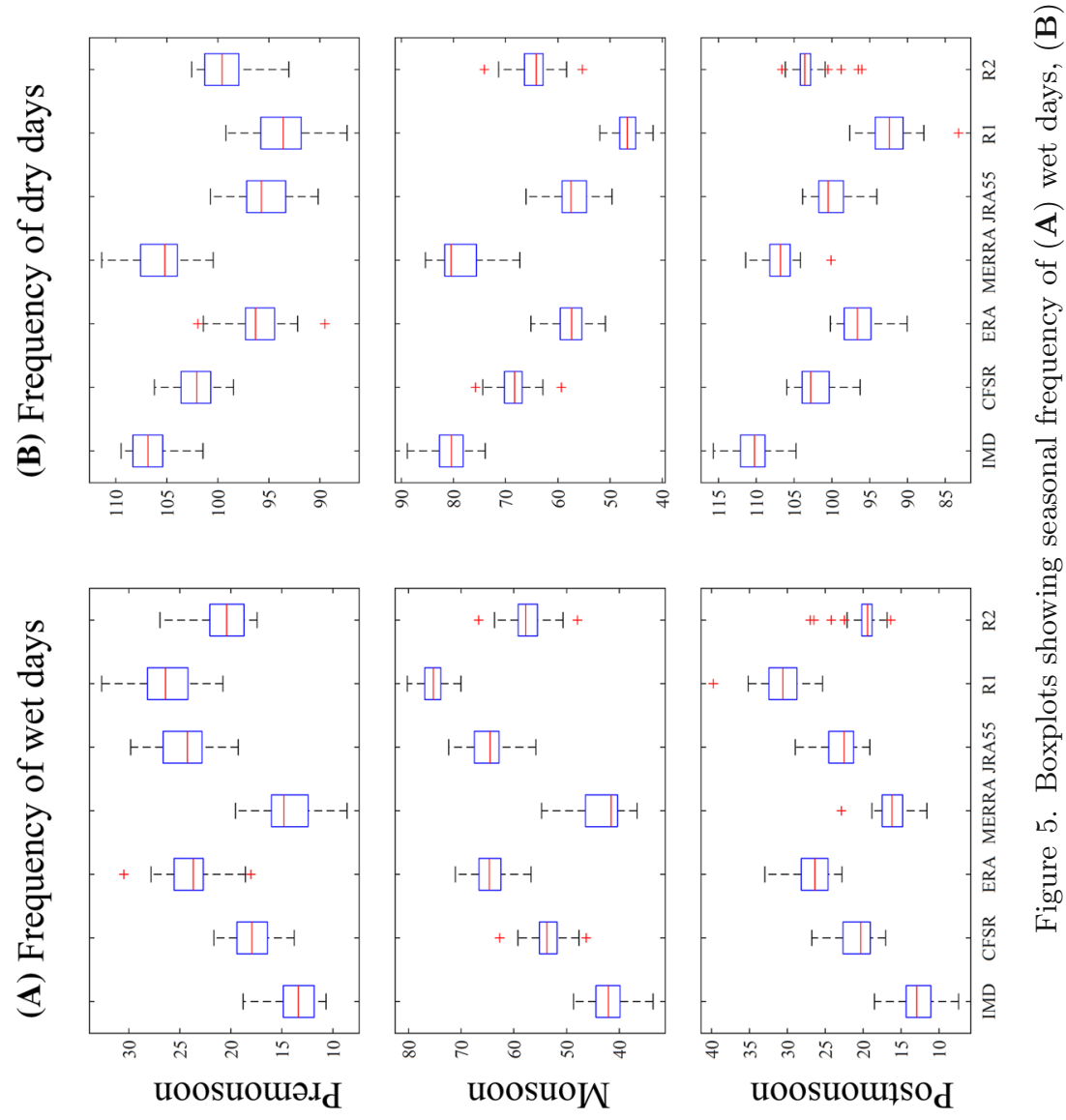
post-monsoon (ONDJ) seasons over India. However, significant regional discrepancies can be observed in all reanalysis products, especially along high rainfall regions such as foothills of Himalayas, northeastern India and the Western Ghats. MERRA-Land is found to be roughly in agreement with IMD data. The variation in precipitation in the monsoon (JJAS) season has not been captured properly by any of the reanalyses. ERA-Interim overestimates the monsoon rainfall in the Western Ghats and the eastern half of the country.
Bosilovich et al. (2008) associated the wet bias to the overestimation of moisture content and precipitable water in the ERA-Interim observation system.

The frequency of wet spells over India shows similar pattern as the wet days, with most of central India experiencing more wet spells during JJAS. All reanalyses mostly underestimate the frequency of wet spells over India, especially in the central and eastern coastal regions during monsoon. NCEP datasets, in particular, highly
(A) TREND IN WET DAYS
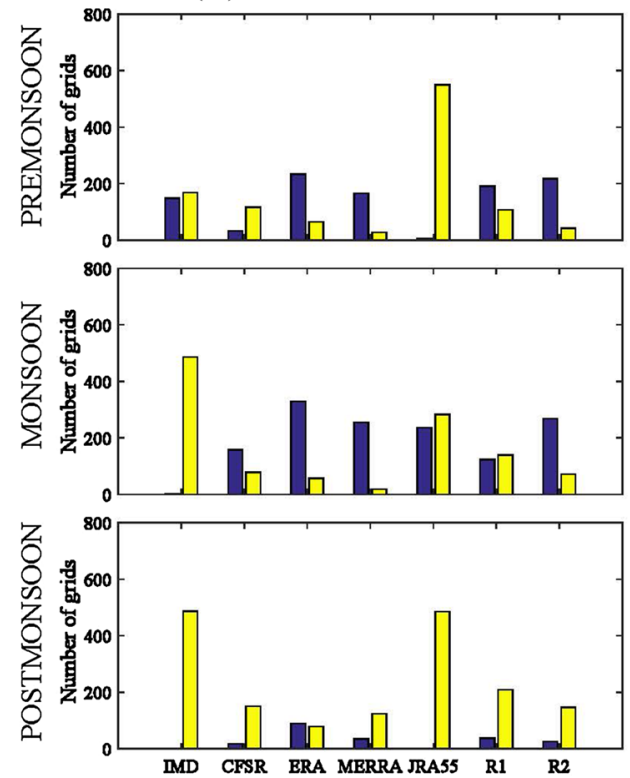

(B) TREND IN WET SPELL
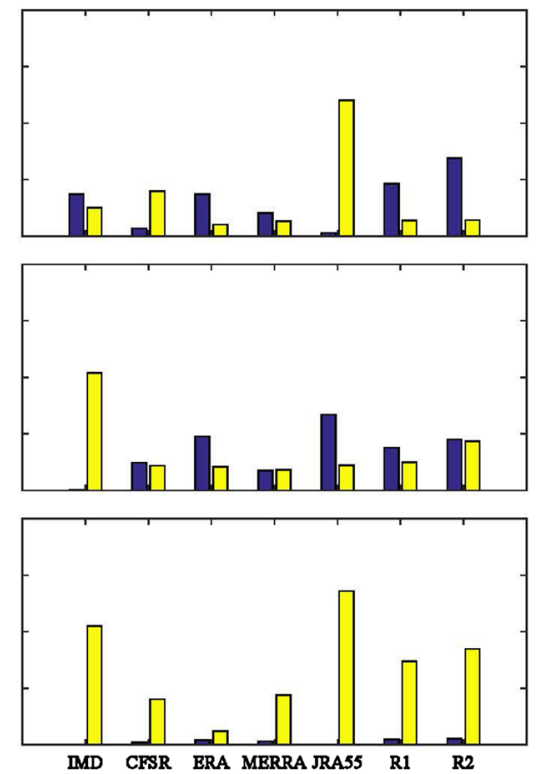

positive trend $\square$ negative trend

(C) TREND IN DRY DAYS
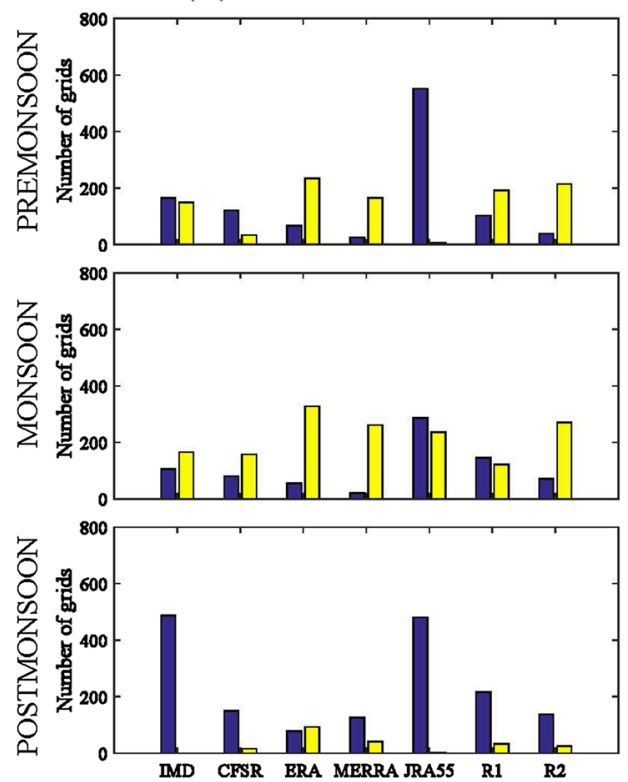

(D) TREND IN DRY SPELL
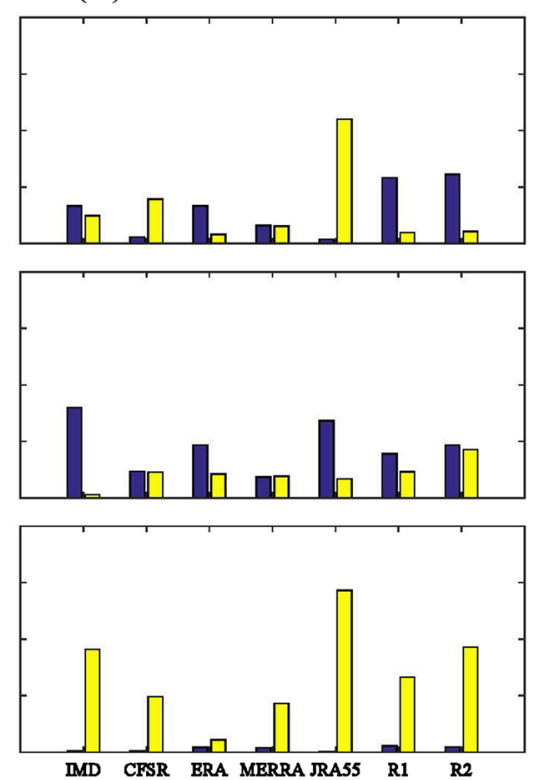

Figure 6. Seasonal trends in the frequency of (A) wet days, (B) wet spell, (C) dry days and (D) dry spell for all reanalyses. 
underestimate wet spells during monsoon, followed by ERA-Interim and JRA-55, while MERRA-Land overestimates frequency of wet spell over entire southern peninsula and underestimate over portions of eastern India. During FMAM, the reanalyses mostly overestimate the frequency of wet spells, while NCEP R1 and CFSR underestimate over most of the regions.

Trend analysis. The non-parametric MannKendall test was used to find the trend in the frequency of wet days and spells in the IMD data and reanalyses from 1980-2013. During FMAM, a positive (negative) trend in the frequency of wet days and spells is observed in the southern (northern) region, while over $70 \%$ of India showed no trend in IMD data. During JJAS, a positive trend in the frequency of wet days (wet spells) is observed over $14 \%(25 \%)$ of the grids, while a negative trend was observed over $10 \%$ (1\%) of the grids. However, both wet days and spells are found to follow a negative trend in ONDJ, over the central part of India. Figure 6 shows the seasonal trend in
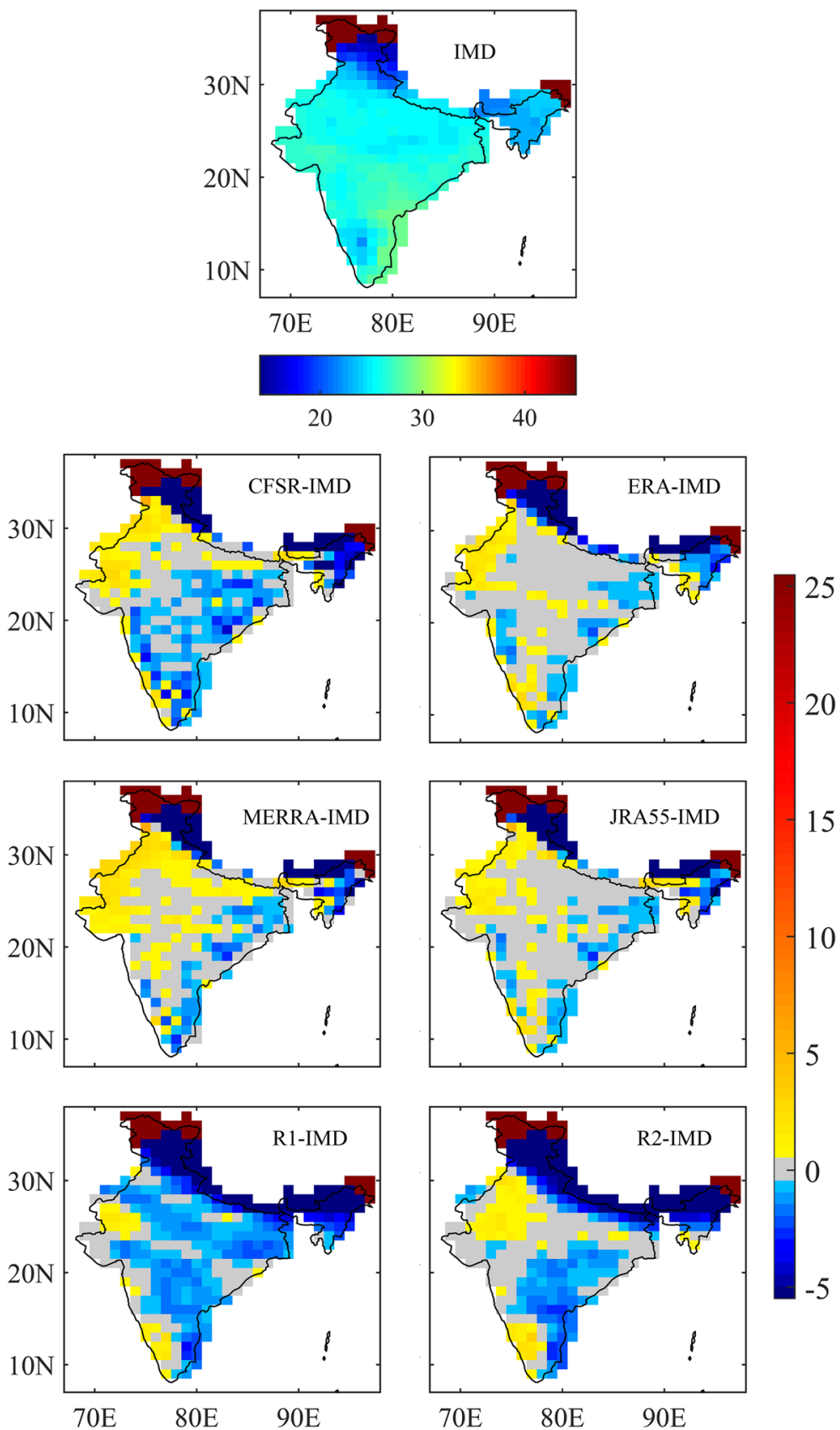

Figure 7. Spatial distribution of long term mean annual temperature $\left({ }^{\circ} \mathrm{C}\right)$ of IMD gridded data from 1980 to 2013 ; long term mean temperature difference of various datasets with respect to IMD gridded dataset are also shown. Figures show that ERA-Interim and JRA-55 seem to provide better results than CFSR and MERRA for long term mean annual temperature. 
the frequency of wet and dry days and spells in the reanalyses in the form of bar charts. None of the reanalyses were able to correctly match the trend pattern of wet days and spell. Especially, JRA-55 dataset completely failed to replicate the trend in precipitation patterns. During FMAM, all reanalyses show a positive trend in frequency of wet spells over southern peninsula, CFSR and JRA-55 showed a negative trend (see supplementary figures S2, S4, S6 and S8 for spatial plots of trend in wet and dry days and spell for all reanalyses). The inability of the reanalysis products in representing trends could be due to the change in observation systems, introduced during the advancements in satellite technology. For instance, the introduction of advanced microwave sounding unit A (AMSU-A) in 1998, may be the reason for spurious trend in MERRA (Robertson et al. 2011). However, the performance of MERRALand in reproducing the general characteristics of precipitation over India have been found to be better than other reanalyses in this study. This is possibly because of the usage of gauge based GPCP v2.1 pentad timescale precipitation data to correct the original MERRA precipitation forcing in the MERRA-Land-only component. Significant changes were also introduced in the catchment model parameters in the MERRA-Land model, thereby eliminating the previously known deficiencies in MERRA reanalysis (Reichle 2011).

\subsection{Analysis of temperature characteristics}

\subsubsection{Mean annual temperature}

The spatial distribution of the mean annual temperature over India for IMD data and reanalyses is shown in figure 7 . Highest mean temperature is observed over the southern coast and northwestern arid region, while lowest mean temperature occurs over northernmost India. All products exhibit a similar pattern of temperature distribution over India. In general, all reanalyses underestimate the temperature over the northeastern and southern India, and overestimate over northwestern arid regions. NCEP R1 and R2 highly underestimate the temperature over most of India. While ERA-Interim and JRA-55 capture temperature variability over India to a greater extent, they underestimate the temperature over the foothills of Himalayas and overestimate over northwestern arid regions. CFSR and MERRA-Land overestimate temperature over northwestern India and underestimate over the eastern half. Shah and Mishra (2014) reported that most reanalyses exhibit cold bias in the northwestern part of
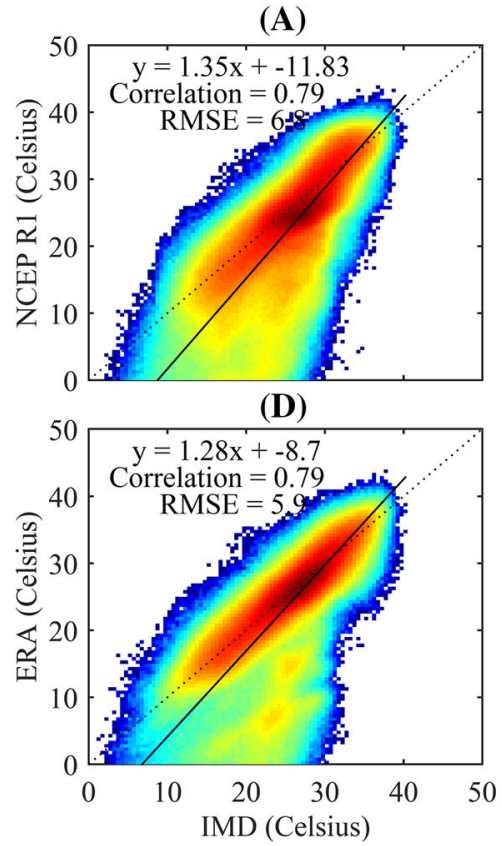

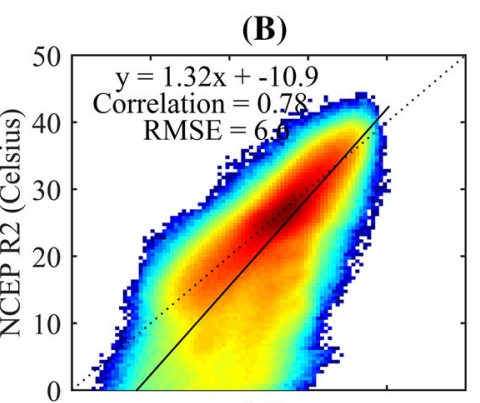

(E)

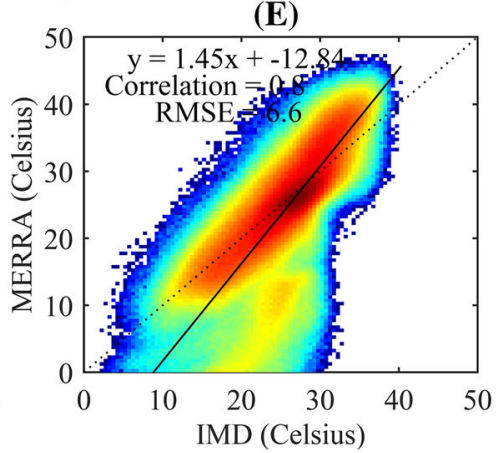

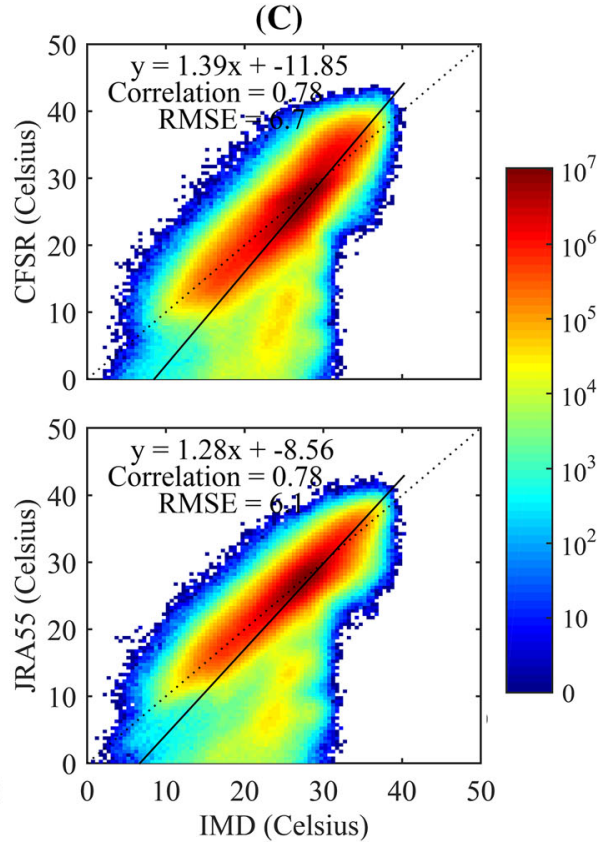

Figure 8. Density scatter plots of daily temperature values between IMD and other reanalyses for the period 1980-2013. The black dashed line is the 1:1 reference line and solid line is the best fit line between IMD and reanalysis data. The colour bar shows counts per $0.5 \mathrm{~mm}$ bin. 


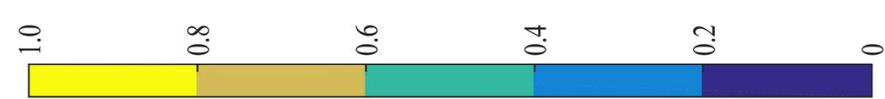

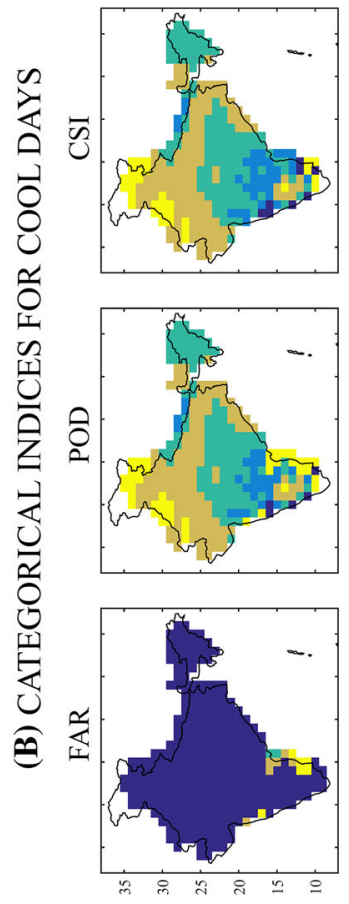

Iy dGJN
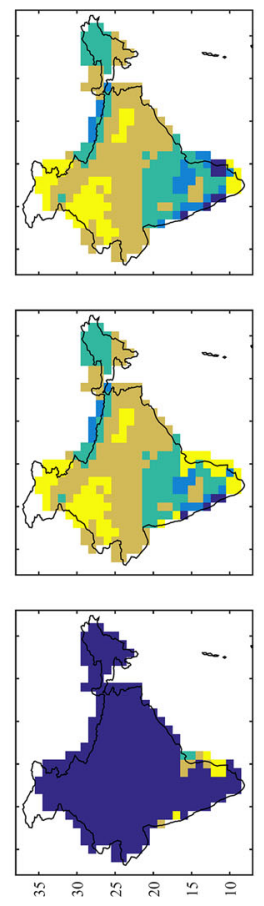

гข dقJN
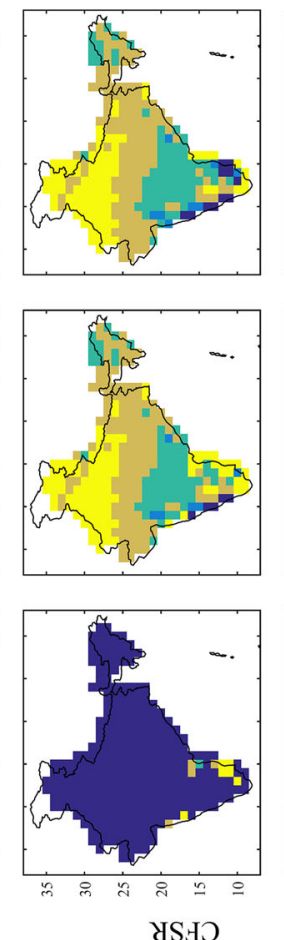

บSAว
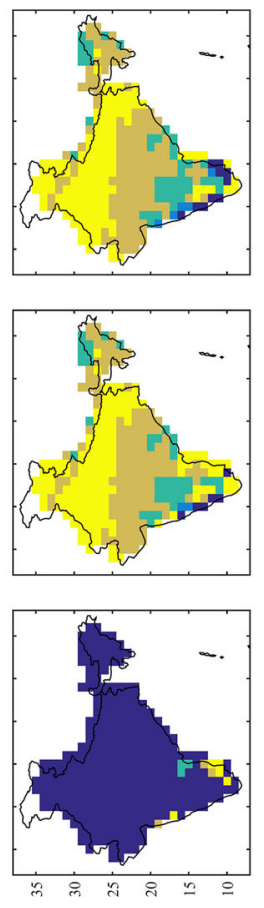

Vyㅂ
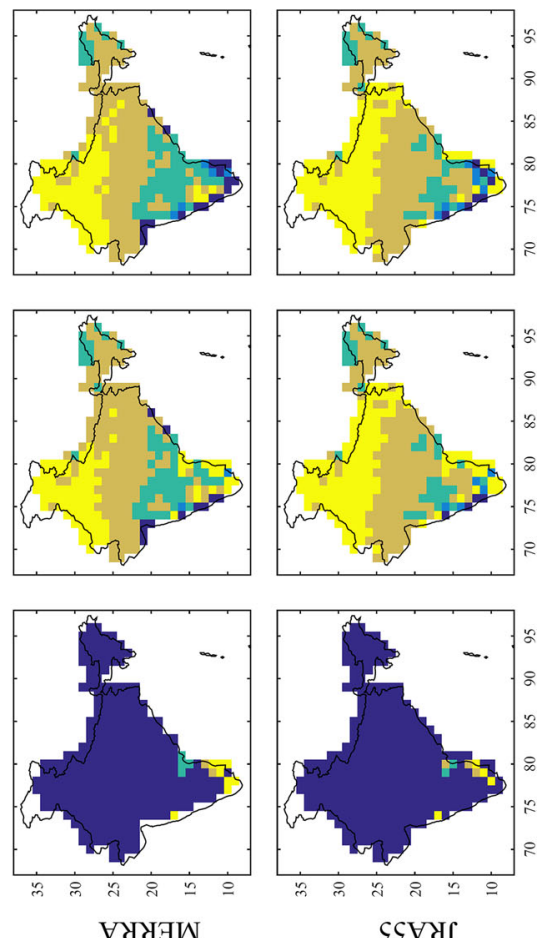

ऽऽVI
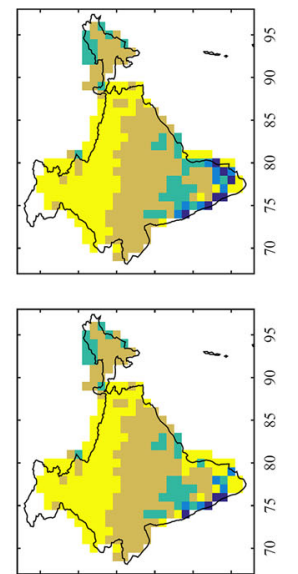

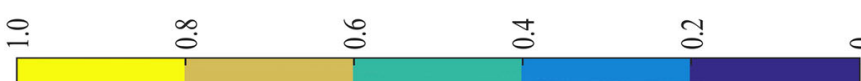

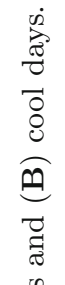

晃
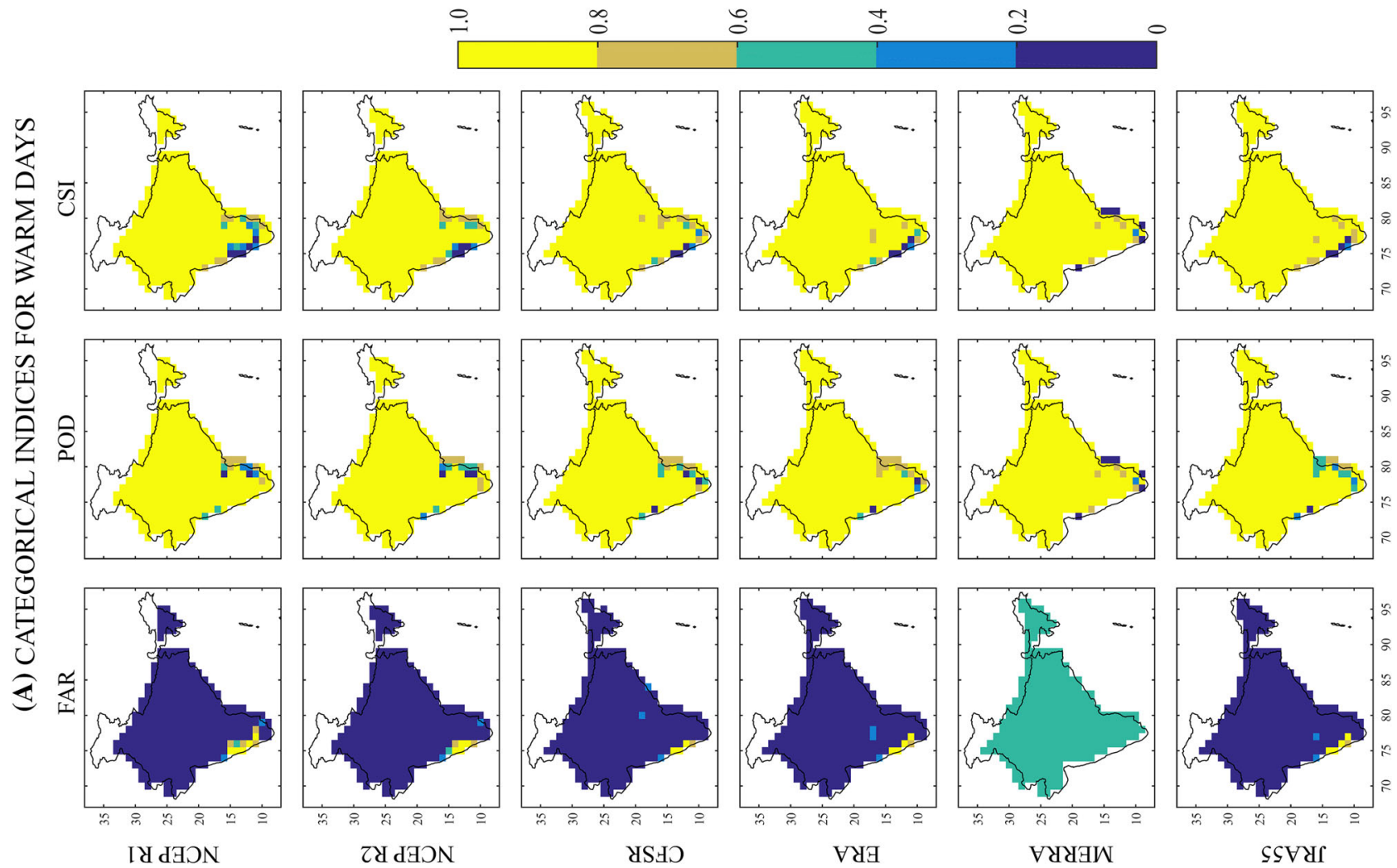
the country. They attributed it to the quality of observational data used as well as to bias in monsoonal precipitation. Coarser resolution of the reanalyses may contribute to the spatial variability in temperature bias (Soares et al. 2012). Since temperature and precipitation are closely coupled together during the monsoon season, the precipitation bias in the reanalyses may cause bias in the temperature (Shah and Mishra 2014). According to Wang and Zeng (2013), another factor that significantly affects the temperature is the atmospheric boundary layer turbulence and the land surface scheme followed by the reanalyses. ERA-Interim and JRA-55 match the temperature distribution over most of India, and give better results than other reanalyses.

\subsubsection{Daily temperature analysis: Statistical indices}

The general agreement between IMD and reanalyses data can be visualized as density scatter plot shown in figure 8 . The linear equation, correlation coefficient and root mean square error are also displayed along with the scatter plots. All reanalyses show nearly similar spread and correlation. NCEP R1, NCEP R2, CFSR, ERA-Interim, MERRALand and JRA-55 exhibited RMSE values of 6.8, 6.6, 6.7, 5.9, 6.6 and $6.1^{\circ} \mathrm{C}$, respectively. Among the datasets, ERA-Interim and JRA-55 show relatively lower RMSE.

\subsubsection{Daily temperature analysis: Categorical indices}

Further analysis for detection of warm and cool days is carried out with the help of categorical indices and the spatial plots for the same are shown in figure 9. The POD (FAR) of frequency of warm days is observed to be high (low) for all reanalyses over entire India, except some portions of southern peninsula. All reanalyses show similar values for these indices, except MERRA-Land which shows higher FAR values for warm days. This may be attributed to the existing bias in MERRA temperature data, as seen in figure 7 . The POD of frequency of cool days is high over north India, but decreases gradually towards central and south India, with the lowest values over the Western Ghats. Reanalyses predict the frequency of warm days correctly, but are inferior in predicting cool days, particularly over regions of high precipitation. This can be further verified by CSI values, where the CSI for detection of cool days is lower over the peninsular region and northeast and higher over north India. The variation in categorical indices with increasing threshold values from 15 to $50^{\circ} \mathrm{C}$ is also observed (not shown here, see supplementary figure S18). The ability of the reanalysis products to correctly simulate the temperature patterns decreases with increasing temperature thresholds, as the values of FAR (POD) keeps increasing (decreasing) with increasing threshold values.

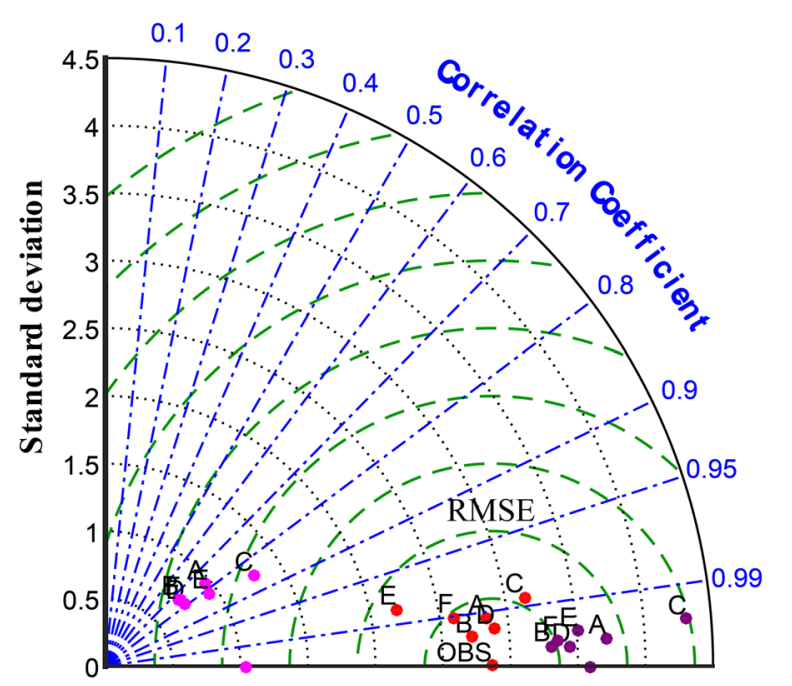

\author{
$\mathrm{A}=\mathrm{CFSR}$ \\ $\mathrm{B}=$ ERA-Interim \\ $\mathrm{C}=$ MERRA-Land \\ $\mathrm{D}=\mathrm{JRA}-55$ \\ $\mathrm{E}=\mathrm{NCEP}-\mathrm{R} 1$ \\ $\mathrm{F}=\mathrm{NCEP}-\mathrm{R} 2$
}

Premonsoon

Monsoon

Postmonsoon

Figure 10. Taylor plot of the seasonal temperature. 

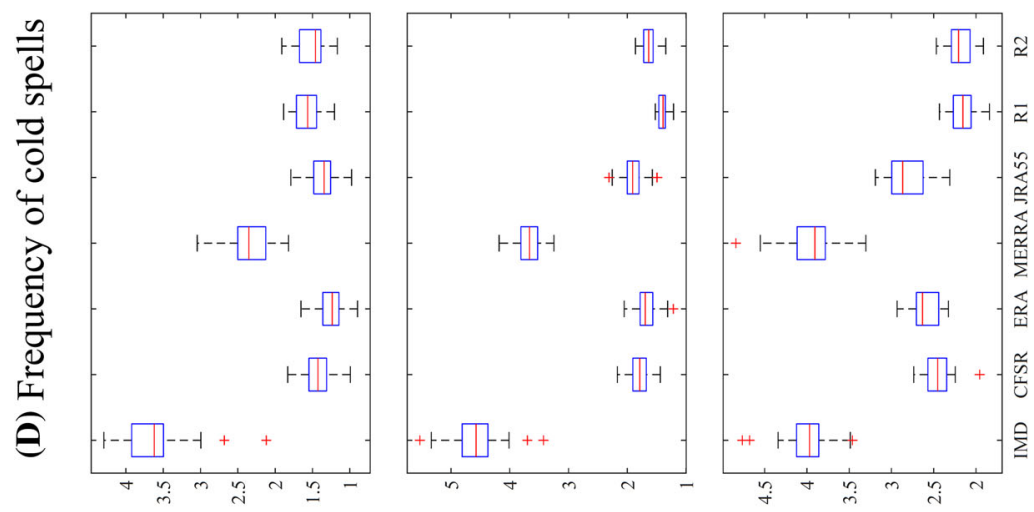

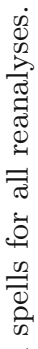
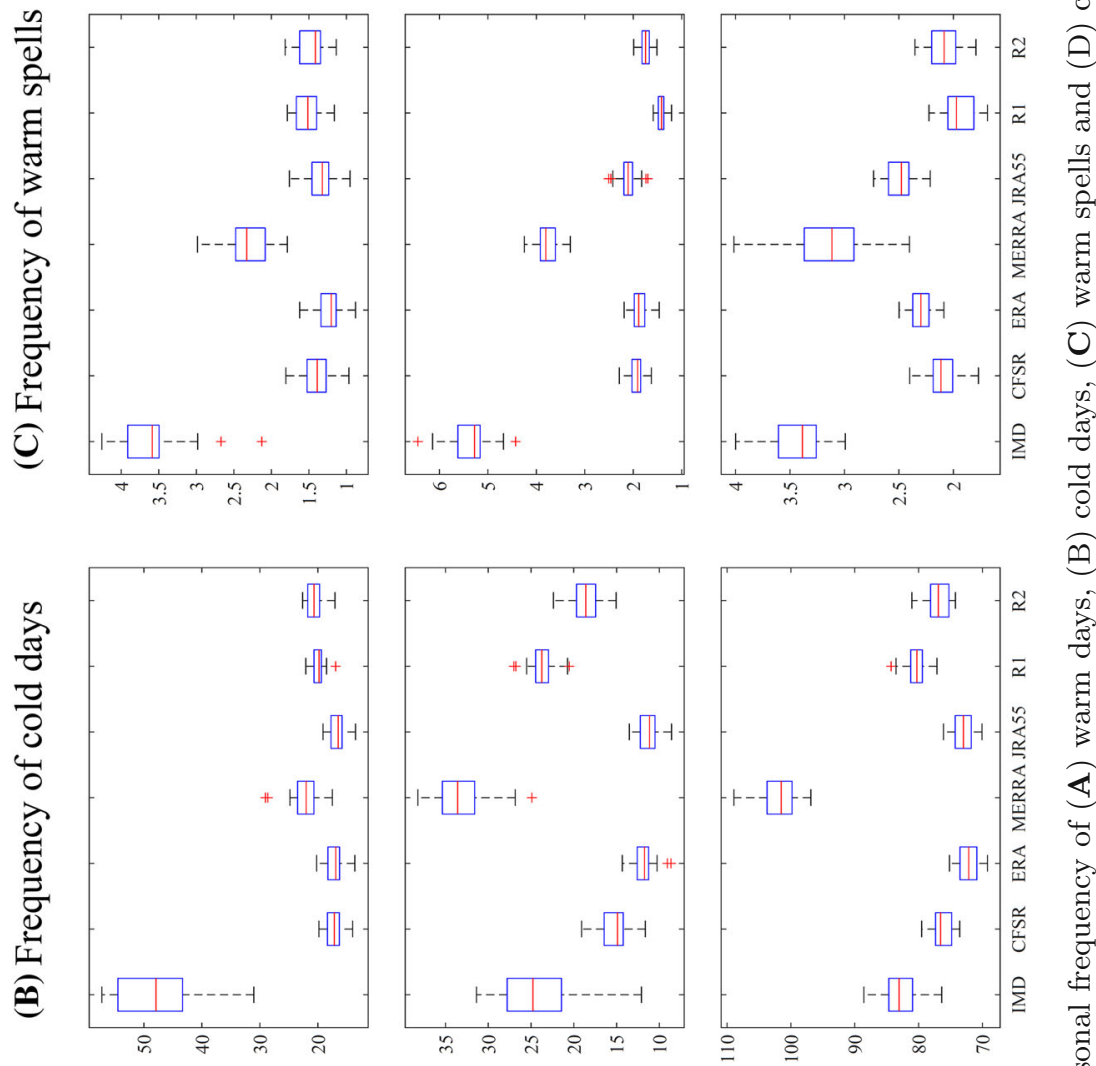

ตี
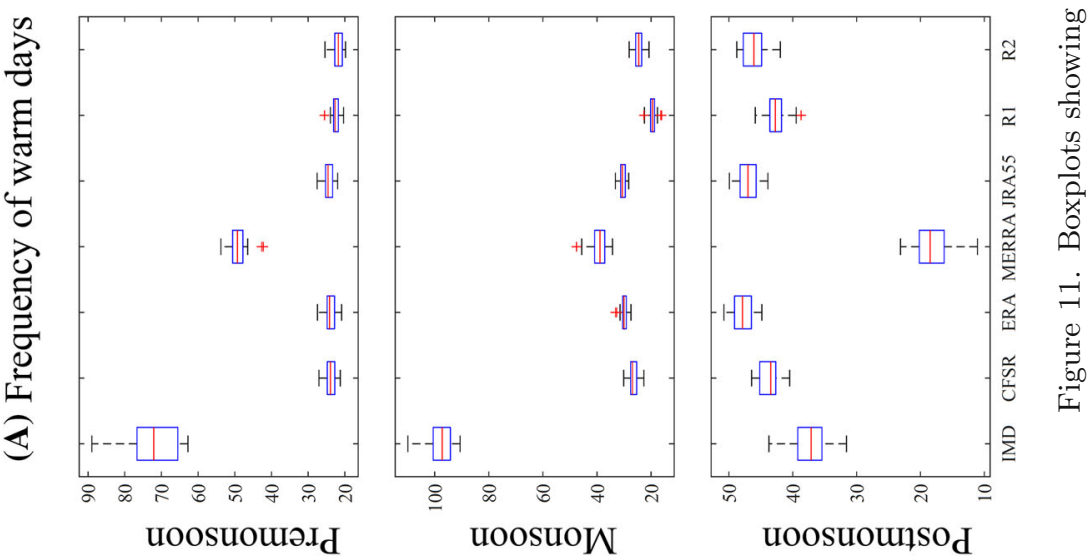


\subsubsection{Seasonal analysis}

The seasonal variation in temperature, in terms of correlation, standard deviation and RMSE, is summarized in Taylor diagram as shown in figure 10. The performance of the reanalyses is considerably better during FMAM and ONDJ, where the correlation is above 0.95 . Among reanalyses, ERAInterim and JRA-55 show good correlation with IMD data throughout all seasons. The seasonal performance of reanalyses is further tested on the basis of factors such as number of warm and cool days and spells.

Spell analysis. India experiences high temperature during the summer season, which occurs around March to May, followed by relatively lower temperatures in monsoon. The central and southern India receive the highest number of warm days during FMAM, whereas the northeastern regions receive least number of warm days
(A) TREND IN WARM DAYS
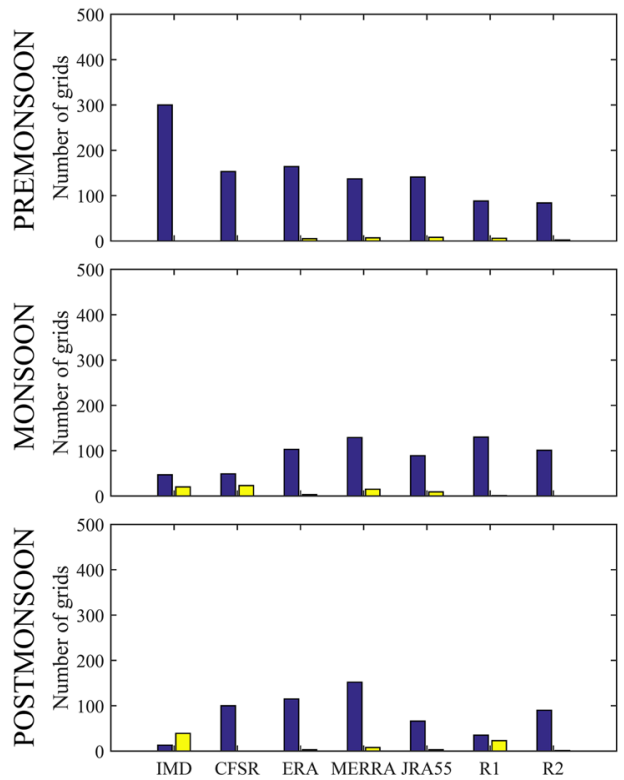

positive trend $\square$ negative trend
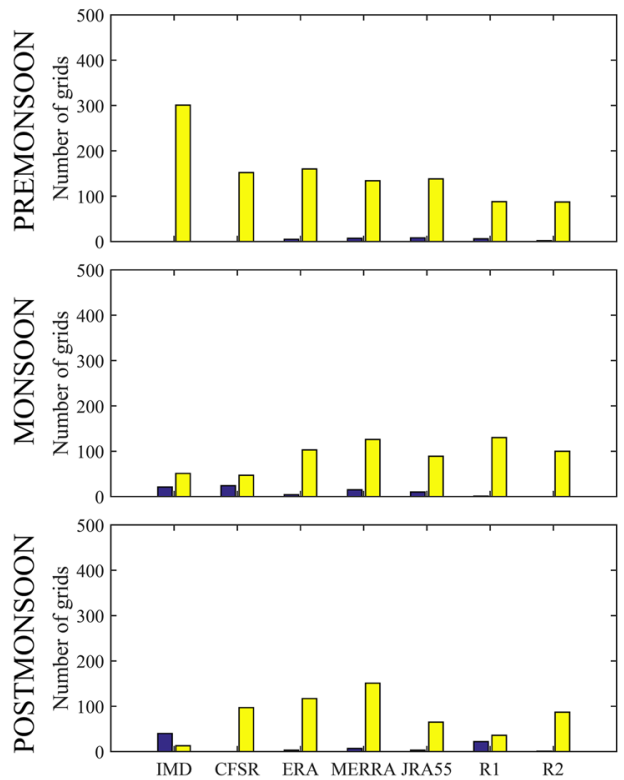

(D) TREND IN COLD SPELL
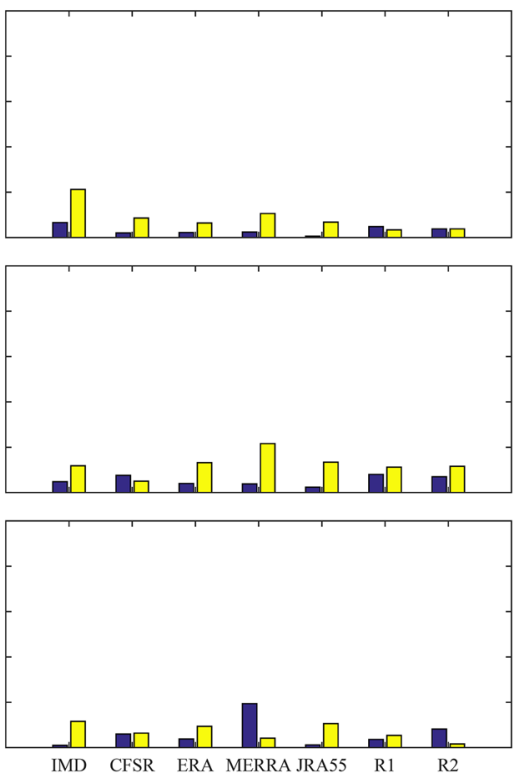

Figure 12. Seasonal trend in the frequency of (A) warm days, (B) warm spells, (C) cool days and (D) cold spells for all reanalyses. 
during this period, along with the Western Ghats and the Himalayan regions. During ONDJ, most of India receives less number of warm days with the onset of winter (see the supplementary figures S9, S11, S13 and S15 for spatial plots of the cool and warm days and spell over India). All reanalyses underestimate the frequency of warm days over foothills of Himalayas and northeastern India throughout all seasons. However, reanalyses overestimate warm days during all seasons over the Western Ghats. NCEP datasets, CFSR and MERRA-Land largely underestimate warm days over India during ONDJ, while ERA-Interim and JRA-55 exhibit closer match with IMD. Boxplots showing the seasonal variation in the frequency of warm and cool days and spells are shown in figure 11. All reanalyses mostly underestimate the frequency of warm days during FMAM and JJAS, and overestimate during ONDJ, particularly MERRA-Land. Similarly, all reanalyses underestimate the frequency of warm and cold spells over India for all seasons. India experiences higher number of warm spells during FMAM. The frequency of warm spells is least during ONDJ, where only a few warm spells are experienced over south India. All reanalyses underestimate the frequency of warm spells during FMAM and ONDJ, while overestimating over Western Ghats. During monsoon, R1, R2 and CFSR highly overestimate the warm spells over central and northeastern India. MERRA-Land overestimates over central India, while underestimate over foothills of Himalayas. Overall, ERAInterim seems to be the best match, followed by JRA-55. However, first generation NCEP datasets appear to be the least matching. Similar results were obtained for the frequency of cold spells during the seasons.

Trend analysis. Seasonal variation in the trend in frequency of warm and cool days and spells is shown in figure 12. It is observed that all reanalyses exhibit positive trend in the frequency of warm days and negative trend in the frequency of cool days. Mann-Kendall trend analysis revealed that $91 \%$ of the grids display a positive trend in the frequency of warm days during FMAM (refer to supplementary figure S14). However, during monsoon season, a positive trend is observed only over parts of Gujarat and northeastern regions (14\% of the grids), while $80 \%$ of grids displayed no significant trend. Similarly, during ONDJ, about $86 \%$ grids show no trend, while a negative trend is observed over central India (12\% of the grids) (see supplementary figures S10, S12, S14 and S16 for spatial distribution of trend for cool and warm days and spells). Reanalyses could only partially be able to capture the trend patterns shown in IMD data during FMAM. For instance, the positive trend in frequency of warm days is only observed over northern half of India in the reanalyses. However, the reanalyses failed to match the trend pattern during JJAS and ONDJ. None of the products managed to accurately match the trend pattern during seasons. For warm spells, about $60 \%$ grids showed no trend during FMAM, in the observed data. However, $29 \%$ grids showed negative trend, mostly over central India. Similarly, a negative trend is observed during JJAS and ONDJ over northeast India (19 and 12\% grids, respectively), while no significant trend was observed over most of India. None of the reanalysis datasets is able to match the trend pattern in warm spell frequency during the seasons.

\section{Conclusions}

The objective of this study was to compare different reanalyses over India in terms of their performance in capturing the mean as well as spatiotemporal variability in precipitation and temperature over India. Six reanalyses: National Centre for Environmental Prediction (NCEP) Reanalysis 1, NCEP-DOE AMIP-2 reanalysis, Climate Forecast System Reanalysis (CFSR), the European Centre for Medium-Range Weather Forecasts (ECMWF), Interim reanalysis (ERA-Interim), the Modern-Era Retrospective analysis for Research and Applications Land model (MERRA-Land) and the Japan Meteorological Agency (JMA) 55-yr reanalysis (JRA-55) were used in this study with regard to the seasonal (FMAM, JJAS and ONDJ) precipitation and temperature variability over the period of 34 yrs from 1980 to 2013. The performances of these reanalyses were compared with the India Meteorological Department (IMD) gridded rainfall and temperature data over India. Several statistical and categorical indices were used to examine and establish the reliability of the reanalyses in reproducing precipitation and temperature patterns over India. The major findings of this study are summarized below:

(1) All the reanalyses performed reasonably well in capturing the major characteristics of seasonal precipitation and temperature variation. 
However, over geographically complex regions having scarce data, significant regional and seasonal differences exist between the reanalyses and the reference data.

(2) While, all reanalyses show good correlation for precipitation and temperature during monsoon season, overall assessment based on the seasonal analysis of spells and trend over India highlights the inefficiency of any particular reanalysis in satisfactorily capturing both precipitation and temperature characteristics over India. For example, MERRALand showed better skill for precipitation estimates than other reanalyses, but lacked similar performance for temperature estimates.

(3) Seasonal analysis for precipitation variability showed that all reanalyses overestimate precipitation over most of India, especially during JJAS. NCEP datasets, ERA-Interim and JRA-55 overestimate precipitation, while MERRA-Land gives better result, although it underestimates precipitation over northernmost and some regions of northeast India. During FMAM and ONDJ, all reanalyses overestimate precipitation, especially over southern peninsular regions.

(4) Highest overestimation is seen in the JRA-55 and NCEP datasets. The correlation for precipitation during FMAM is found to be around 0.8 for all datasets, whereas, it is found to be around 0.93 for ONDJ. NCEP R1 and R2, being the earliest released datasets, performed least among reanalyses.

(5) A significant amount of improvement over $\mathrm{R} 1$ and $\mathrm{R} 2$ can be seen in CFSR, which may be attributed to the advanced model physics and data assimilation methods. However, the performance of CFSR over India is still inferior.

(6) Large disparities in precipitation trend patterns in IMD data and reanalyses were highlighted in the Mann-Kendall analysis, revealing the inability of the reanalyses in capturing trend patterns.

(7) MERRA-Land is found to give best results for precipitation for all seasons. This is possibly due to correction of original MERRA precipitation forcing in the MERRA-Land-only component using gauge based GPCP v2.1 pentad timescale precipitation data.

(8) In case of temperature variation, all datasets seem to underestimate temperatures over the foothills of Himalayas. Additionally, CFSR and MERRA-Land seem to overestimate (underestimate) the high (low) temperatures over the northwestern (southeastern) regions of India.

(9) Seasonal temperature variation shows overestimation (underestimation) in the FMAM (ONDJ) in all datasets especially over the northwestern (southern) regions of India.

(10) ERA-Interim and JRA-55 manage to capture the variation in temperature quite well over most of India. Both ERA-Interim and JRA55 utilize 4D-VAR data assimilation scheme, which is the most advanced method among reanalyses.

(11) The overall seasonal correlation for temperature for all datasets is found to be quite high, but based on all statistical indices, it can be concluded that ERA-Interim and JRA-55 give better results for temperature as compared to NCEP datasets and MERRA-Land.

(12) None of the reanalyses were able to capture the trend pattern in IMD for temperature.

Based on our study, MERRA-Land showed the best results for precipitation, whereas ERA-Interim and JRA-55 performed better in case of temperature over India. The results of this study might be useful to the researchers, who want to use these reanalyses for spatio-temporal analysis and climate change studies. While the results of this study highlight the strengths as well as limitations of the reanalysis products over India, further effort in developing new innovative methodologies and in-depth analysis of the performance of reanalyses would be required to better assess the robustness, accuracy and applicability of these datasets.

\section{Acknowledgements}

The authors would like to thank ECMWF, JMA, NASA and NCEP for providing access to their corresponding reanalyses datasets. The authors would also like to thank Indian Institute of Technology, Delhi (IITD) for supporting this study. They are also thankful to the anonymous reviewers for their valuable comments.

\section{References}

Bosilovich M G, Chen J, Robertson F R and Adler R F 2008 Evaluation of global precipitation in reanalyses; J. Appl. Meteor. Climatol. 47 2279-2299.

Blacutt L A, Herdies D L, de Concalves L G G, Vila D A and Andrade M 2015 Precipitation comparison of CFSR, 
MERRA, TRMM3B42 and combined scheme datasets in Bolivia; Atmos. Res. 163 117-131.

Chaudhary S, Dhanya C T and Vinnarasi R 2017 Dry and wet spell variability during monsoon in gauge-based gridded daily precipitation datasets over India; J. Hydrol. 546 204-218.

Chen G, Iwasaki T, Qin H and Sha W 2014 Evaluation of the warm-season diurnal variability over East Asia in recent reanalyses JRA-55, ERA-Interim, NCEP CFSR, and NASA MERRA; J. Clim. 27 5517-5537.

Dash S K and Kjellstrom T 2011 Workplace heat stress in the context of rising temperature in India; Curr. Sci. 101 496-503.

Dash S K, Kulkarni M A, Mohanty U C and Prasad K 2009 Changes in the characteristics of rain events in India; J. Geophys. Res. 114 D10109, https://doi.org/10.1029/ 2008JD010572.

Dee D P, Uppala S M, Simmons A J, Berrisford P, Poli P and Kobayashi S et al. 2011 The ERA-Interim reanalysis: Configuration and performance of the data assimilation system; Quart. J. Roy. Meteor. Soc. 137(656) 553-597.

Deshpande N R, Kothawale D R and Kulkarni A 2016 Changes in climate extremes over major river basins of India; Int. J. Climatol, https://doi.org/10.1002/joc.4651.

Dhanya C T and Villarini G 2017 An investigation of predictability dynamics of temperature and precipitation in reanalysis datasets over the continental United States; Atmos. Res. 183(1) 341-350.

Ebita A, Kobayashi S, Ota Y,Moriya M, Kumabe R, Onogi K, Harada Y, Yasui S, Miyaoka K, Takahashi K and Kamahori H 2011 The Japanese 55-year Reanalysis "JRA55": An interim report; Sola 7 149-152.

Epifani C, Esposito S and Vento D 2004 Persistence of wet and dry spells in Italy: First results in Milano from 1858 to 2000; Proceedings of the 14th International Conference on Clouds and Precipitation and International Association of Meteorology and Atmospheric Sciences, Bologna, pp. $18-24$.

Hodges K I, Lee R W and Bengtsson L 2011 A comparison of extra tropical cyclones in recent reanalysis ERA-Interim, NASA MERRA, NCEP CFSR, and JRA-25; J. Clim. 24 4888-4906.

Kalnay E, Kanamitsu M, Kistler R, Collins W, Deaven D, Gandin L, Iredell M, Saha S, White G, Woollen J and Zhu Y 1996 The NCEP/NCAR 40-year reanalysis project; Bull. Am. Meteorol. Soc. 77(3) 437-471.

Kanamitsu M, Ebisuzaki W, Woollen J, Yang S K, Hnilo J J, Fiorino M and Potter G L 2002 NCEP-DOE AMIP-ii reanalysis (r-2); Bull. Am. Meteor. Soc. 83(11) 1631-1643.

Kang S and Ahn J 2015 Global energy and water balances in latest reanalyses; Asia-Pac. J. Atmos. Sci. 51(4) 293302.

Kar S C and Rana S 2014 Interannual variability of winter precipitation over northwest India and adjoining region: Impact of global forcings; Theor. Appl. Climatol. 116609 623.

Kishore P, Jyothi S, Basha G, Rao S V B, Rajeevan M, Velicogna I and Sutterley T C 2016 Precipitation climatology over India: Validation with observations and reanalysis datasets and spatial trends; Clim. Dyn. 46(1-2) 541-556.
Kobayashi S, Yukinari O T A, Harada Y, Ebita A, Moriya M, Onoda H, Onogi K, Kamahori H, Kobayashi C, Miyaoka K and Takahashi K 2015 The JRA-55 reanalysis: General specifications and basic characteristics; J. Meteorol. Soc. Japan. Ser. II 93(1) 5-48.

Lin R, Zhou T and Qian Y 2014 Evaluation of global monsoon precipitation changes based on five reanalysis datasets; J. Clim. 27 1271-1289.

Lorenz C and Kunstmann H 2012 The hydrological cycle in three state-of-the-art reanalyses: Intercomparison and performance analysis; J. Hydrometeor. 13 1397-1420.

Manzanas R, Amekudzi L K, Preco K, Herrera S and Gutierrez J M 2014 Precipitation variability and trends in Ghana: An intercomparison of observational and reanalysis products; Clim. Change $\mathbf{1 2 4} 805-819$.

Misra V, Pantina P, Chan S C and DiNapoli S 2012 A comparative study of the Indian monsoon hydroclimate and its variations in three reanalyses; Clim. Dyn. 391149 1168 .

Outten S, Davy R and Isau I 2013 Eurasian winter cooling: Intercomparison of reanalyses and CMIP5 data sets; Atmos. Oceanic Sci. Lett. 6(5) 324-331.

Pai D S and Rajeevan M 2007 Indian summer monsoon onset: Variability and prediction, Nat. Clim. Centre, India Meteorological Department.

Pai D S, Sridhar L, Rajeevan M, Sreejith O P, Satbhai N S and Mukhopadhyay B 2014 Development of a new high spatial resolution $(0.25 \times 0.25)$ long period (1901-2010) daily gridded rainfall data set over India and its comparison with existing data sets over the region; Mausam $\mathbf{6 5}(\mathbf{1})$ $1-18$.

Rajeevan M, Gadgil S and Bhate J 2010 Active and break spells of the Indian summer monsoon; J. Earth Syst. Sci. 119(3) 229-247.

Rana S, Mcgregor J and Renwick J 2015 Precipitation seasonality over India subcontinent: An evaluation of gauge, reanalysis and satellite retrievals; J. Hydrometeor. 16 631-651.

Reichle R H, Koster R D, Lannoy G J, Forman B A, Liu Q, Mahanama S P P and Toure A 2011 Assessment and enhancement of MERRA-land surface hydrology estimates; J. Clim. 24 6322-6338.

Rienecker M M, Suarez M J, Gelaro R, Todling R, Bacmeister J, Liu E, Bosilovich M G, Schubert S D, Takacs L, Kim G K and Bloom S 2011 MERRA: NASA's modernera retrospective analysis for research and applications; $J$. Clim. 24 3624-3648.

Robertson F R, Bosilovich M G, Chen J and Miller T L 2011 The effect of satellite observing system changes on MERRA water and energy fluxes; J. Clim. 24(20) $5197-$ 5217.

Saha S, Moorthi S, Pan H L, Wu X, Wang J, Nadiga S, Tripp P, Kistler R, Woollen J, Behringer D and Liu H 2010 The NCEP Climate Forecast System Reanalysis; Bull. Am. Meteor. Soc. 91 1015-1057.

Santer B D, Wigley T M, Simmons A J, Kållberg P W, Kelly G A, Uppala S M, Ammann C, Boyle J S, Brüggemann W, Doutriaux C and Fiorino M 2004 Identification of anthropogenic climate change using a second-generation reanalysis; J. Geophys. Res. (Atmos.) 109(D21). 
Shah R and Mishra V 2014 Evaluation of the reanalysis products for the monsoon season droughts in India; $J$. Hydrometeor. 15 1575-1591.

Shepard D 1968 A two-dimensional interpolation function for irregularly-spaced data. In: Proceedings of the 1968 23rd ACM National Conference, ACM, pp. 517-524.

Soares P M, Cardoso R M, Miranda P M, de Medeiros J, Belo-Pereira M and Espirito-Santo F 2012 WRF high resolution dynamical downscaling of ERA-Interim for Portugal; Clim. Dyn. 39 2497-2522.

Srivastava A K, Rajeevan M and Kshirsagar S R 2009 Development of a high resolution daily gridded temperature data set (1969-2005) for the Indian region; Atmos. Sci. Lett. 10 249-254.

Sushama L, Said S B, Khaliq M N, Kumar D N and Laprise R 2014 Dry spell characteristics over India based on IMD and APHRODITE datasets; Clim. Dyn. 43(12) 3419 3437 .

Taylor K E 2001 Summarizing multiple aspects of model performance in a single diagram; J. Geophys. Res. 106(D7) $7183-7192$.

Corresponding editor: ABHIJIT MukherJeE
Tilya F and Mhita M 2007 Frequency of wet and dry spells in Tanzania. Clim. and Land Degradation, Springer, pp. 197-204.

Uppala S M, Kållberg P W, Simmons A J, Andrae U, Bechtold V D, Fiorino M, Gibson J K, Haseler J, Hernandez A, Kelly G A and Li X 2005 The ERA40 re-analysis; Quart. J. Roy. Meteorol. Soc. 131(612) 2961-3012.

Vinnarasi R and Dhanya C T 2016 Changing characteristics of extreme wet and dry spells of Indian monsoon rainfall; J. Geophys. Res. (Atmos.) 121(5).

Vose R S, Applequist S, Menne M J, Williams C N and Thorne P 2012 An intercomparison of temperature trends in the U.S. historical climatology network and atmospheric reanalyses; Geophys. Res. Lett. 39 L10703.

Wang A and Zeng X 2013 Development of global hourly $0.5^{\circ}$ land surface air temperature datasets; J. Clim. (26) 7676-7691.

Wilks D S 2011 Statistical methods in the atmospheric sciences; Vol. 100, Academic Press. 